\title{
Reposition of Forward-to-Backward Input-Output Analysis
}

\author{
Argyrios D. Kolokontes"
}

\begin{abstract}
A common phenomenon that is met in the literature is the fallacious use of traditional quantitative backward-to-forward analysis for the construction of matrices for the forward analysis. The generated deceitful backward-to-forward direct individual indices load to erroneous total sectoral forward linkages indicators (TFLs') and type I for-ward multipliers (t.I-FMs'). Moreover, they are used in the literature as a part for other "mixed" indicators adding correct backward to incorrect forward measurements, leading the analysts to inappropriate deductions as regards the frontloading concernment of various productive sectors in an economy. In order to be tackled this situation an "ad-justed" quantitative forward-to-backward approach must be adopted, as a necessary complementary part for a con-summate growing planning. The paper scrutinizes and concretizes this proposed adjusted approach, both in theory and in practice, via an empirical application. The adjusted forward type I multipliers are nominated and calculated, escorting this analysis.
\end{abstract}

Keywords: I-O analysis; adjusted forward-to-backward approach; forward linkages' indices; type I forward multipliers.

JEL classification: C18; C51; C52; C67; O21.

\section{INTRODUCTION}

The input-output (I-O) analysis is recognized from the researchers as a sound tool for the studies on the structures of economic productive networks, the sectoral growing predictions and the enactment of priorities for the developmental patterns (Almon, 1966; Jensen, 1976, pp. 39-48; Briassoulis, 1991; West, 1995; Sonis and Hewings, 1998; de Mesnard, 1999, 2000b, 2000a; Polenske, 2004; Bonfiglio, 2005, pp. 39-48; Meng et al., 2009; A. H. Bekhet, 2010; Belegri-Roboli and Markaki, 2010; A. H. Bekhet, 2011; Belegri-Roboli et al., 2011a; Trinh et al., 2012; Hristu-Varsakelis et al., 2012; Mastronardi et al., 2012; Humavindu and Stage, 2013; Pnevmatikos et al., 2013; Ramos and Moreno, 2013; Zhong and

\footnotetext{
"Department of Regional and Cross-Border Development Studies and Department of Statistics and Insurance Sciences, School of Economic Sciences, University of Western Macedonia, Kozani, Greece; e-mail: affo0105@uowm.gr and argiriskol@gmail.com (corresponding author).
} 
Tadayuki, 2013; Baranov et al., 2014; Choi et al., 2014; Trinh and Phong, 2014; Economakis et al., 2015; Loizou et al., 2015; H. A. Bekhet et al., 2016; Belegri-Roboli et al., 2016; Kelly et al., 2016; Freytag and Fricke, 2017; Kakderi and Tasapoulou, 2017; Trinh, 2017; Yasmin and Bekhet, 2017; Giannakis and Mamuneas, 2018; Kolokontes et al., 2018; Mariolis et al., 2018; Mariolis et al., 2019; Nhung et al., 2019a; Nhung et al., 2019b; Romero et al., 2019; Teves, 2019; Thai and Trinh, 2019; Thai et al., 2019; de Lima Almeida and de Freitas Balanco, 2020; Ferreira et al., 2020; Guang and Wen, 2020; Hung et al., 2020; Thai et al., 2020; Trinh, 2020; Hastuti et al., 2021; Markaki and Economakis, 2021).

The most common distinction of I-O models is between the "demand-driven" and the "supply-driven" models (Yamada, 1961; F Giarratani, 1976; Jones, 1976; F. Giarratani, 1980; Cronin, 1984; Bon, 1986; Oosterhaven, 1988; Gruver, 1989; Miller, 1989; Oosterhaven, 1989; Deman, 1991; Bon and Bing, 1993; Lahr, 1993; de Mesnard, 1995; Bon and Yashiro, 1996; Oosterhaven, 1996; de Mesnard, 2002b; Adamou, 2007; A. H. Bekhet, 2010; Guerra and Sancho, 2010; Ramos and Moreno, 2013; Choi et al., 2014; Grassini, 2014; Aroche Reyes and Marquez Mendoza, 2015; Yasmin and Bekhet, 2017; de Mesnard, 2019b; Kolokontes et al., 2019; Oosterhaven, 2019). However this separation is somehow problematic. The demanddriven models reflect the "quantity-oriented" and the "price-oriented Leontief's backward-toforward analysis" (Leontief, 1936b, 1936a, 1937, 1941, 1944, 1951, 1986, 1991; Miller and Blair, 2009; de Mesnard, 2013; Choi et al., 2014; Grassini, 2014; Aroche Reyes and Marquez Mendoza, 2015; de Mesnard, 2016; A. H. Bekhet and Yasmin, 2017; de Mesnard, 2019b, 2019a; Kolokontes et al., 2019; Oosterhaven, 2019; Mariolis and Soklis, 2020), while the supply-driven models are identified to the "price-oriented Ghosh's forward-to-backward approach" (Oosterhaven, 1988, 1989, 1996; Dietzenbacher, 1997; Miller and Blair, 2009; Guerra and Sancho, 2010; Choi et al., 2014; Grassini, 2014; Aroche Reyes and Marquez Mendoza, 2015; de Mesnard, 2016, 2019b; Kolokontes et al., 2019; Oosterhaven, 2019). Albeit the quantityoriented forward-to-backward consideration can be arisen from the seminal idea of "Ghosh's allocation's functions" (Ghosh, 1958), this quantitative approach is not applied in the empirical studies of literature. Ab initio, it must be clarified that in this paper, the terms "quantityoriented" and "quantitative" models are not referred to models that describe transactional flows by physical units, which just present intersectoral quantities visualizations without an easy to use mathematical application, but these terms are used denoting monetary transactions in values models with stable prices and variable quantities. So, for the forthcomings, it must be not forgotten that the values of individual elements of applicable I-O models are the products between the quantities and the prices, and these parameters can be either both changed into the dynamic situations, or can be studied supposing changes only on the quantities, or only on the prices (Soklis, 2014; Kolokontes et al., 2019).

The scarce of quantitative forward-to-backward analysis, on a correct base, has been pointed out from Kolokontes et al. (2019). As a consequence from its absence, two common phenomena are met in the literature. The first is the lack of a pure, unequivocal and accurate frontloading approach for the empirical detection of noticeable sectors in a productive economic nexus as a whole. The second matter is the fallible and deceitful exploitation of individual coefficients that are revealed from the Leontief's backward-to-forward consideration, when these coefficients are used for forward measurements. Although the forward multipliers are a necessary supplementary tool for the developmental planning, however their derivation via the quantitative backward-to-forward Leontief's model channelizes the policy-makers to erroneous evaluations as for the potential importance of 
productive sectors in an economy. The problem had been highlighted from Yamada (1961); Augusztinovics (1970); Bayers (1976); Jones (1976); Cai and Leung (2004); Kolokontes et al. (2019), but it has not really faced yet.

Bayers (1976) had pointed out the problem of fallible derivation of forward linkages indicators (FLs'), but without to turn the interest of researchers from the conventional backward-to-forward (=quantitative Leontief's demand-driven) approach to a suitable "quantitative forward-to-backward approach". The rational incompatible between the coefficients of price-oriented Ghosh's model and them of quantitative Leontief's model has been remarked by de Mesnard (2002a), while Cai and Leung (2004) veered their attention for the construction of FLs' outright from the Ghosh's model. The Ghosh's model (1958) gained publicity through the studies of Augusztinovics (1970) and Jones (1976). Oosterhaven (1988, 1996, 2017), Oosterhaven et al. (2001), Dietzenbacher (1997, 2002) and de Mesnard (2002b) since they seem to agree that the conventional shape of Ghosh's model is a price-model. Moreover, de Mesnard (2016) had asserted the view that the Ghosh's model is redundant, since its operation is overspread from the Leontief's cost-push consideration, for which he has referred that is superfluous too (de Mesnard, 2019a). Oosterhaven (1988, 1989, 2019), notwithstanding he had looked behind from the wall as for the usefulness of Ghosh's model when the value added can be kept static, nevertheless he ended up to a deduction that this view of model is implausible and unrealistic (Lahr, 1993; Guerra and Sancho, 2010; Aroche Reyes and Marquez Mendoza, 2015). Similar inferences have been enunciated by Guerra and Sancho (2010) and de Mesnard (2009, 2016, 2019a).

Such conclusions are met in the literature and are owed to the postulated markets' restrictions that are connected with the models (F. Giarratani, 1980; Cronin, 1984; Deman, 1988; Briassoulis, 1991; Zhong and Tadayuki, 2013; Aroche Reyes and Marquez Mendoza, 2015; Kolokontes et al., 2019). Of course, the productive sectors cannot produce infinite products and the consumers (in or/and out from the borders, individuals or/and governments) cannot consume infinite quantities, but these factors must not impugn the estimated potential sectoral capabilities for multiplicative impacts dispersions. These potential non-weighted effects can be either backward or forward, and must be the base for the policy-makers decisions, together with their weighted expressions that transfer the "potential" to the "indeed feasible" for the various indices taking into consideration the sectoral sizes. The essence of the matter is the measurements to be compatible and comparable (Cronin, 1984; Deman, 1988; Kolokontes et al., 2019). Compatible and comparable backward and forward sectoral multiplicative effects can be contrasted, compared or/and divided, pointing out the sectors that are, either more, or the same strength, as regards their backloading and frontloading multiplicative spillovers, providing simultaneously estimations for the sectoral potential influences (Yamada, 1961; Cronin, 1984; Deman, 1988; Adamou, 2007; Kolokontes et al., 2019). Aroche Reyes and Marquez Mendoza (2015) have also advocated the view that the Ghosh's model has interesting perspectives and it must not be rejected.

The bibliographical applications of Ghosh's model, when they are correct, adhere on the inflationary repercussions of its price-oriented approach, avoiding a quantitative-oriented approach for it, as a solution capable to provide plausible measurements for the frontloading quantitative effects (Oosterhaven, 1988, 1989, 1996; Dietzenbacher, 1997; de Mesnard, 2002b, 2019b, 2019a). The same inappropriate for the derivation of quantitative forward multipliers is the traditional quantitative Leontief's approach. Diachronically, in the literature are registered imprecisions, complications and deterministic errors as for the use of debated 
models owing to the unilateral consideration of their stimuli (exogenous and endogenous); as well as due to their misunderstanding usefulness and the deceitful interpretation of their indicators without to be taken into account their peculiarities, merits and disadvantages (e.g.: Jones, 1976; Sonis et al., 1996; Guo and Hewings, 2001; Oosterhaven and Stelder, 2008; Humavindu and Stage, 2013; Choi et al., 2014; Temurshoev and Oosterhaven, 2014; Freytag and Fricke, 2017). Contemporaneously, quite a few studies are consumed with unnecessary impressive graphics and mathematics, gaining publications, but losing the essence and the logic of simplicity, generating illusions to the readers, the scholars and the policy-makers.

Kolokontes et al. (2019), without to scope to concentrate their interest on this topic, had entered the idea for the "adjusted" forward analysis in an unprocessed initiatory level, "aiming to tease the curiosity of readers, scholars and researchers", as they had said. Moreover, they had clarified their beliefs that the ideas are put on the table and evolved until to end up to a distinct and correct enunciation. Of course, the paradigm with the "simple method of three" in their paper has obviously been referred from them in order to demonstrate the problem, since is intelligible that its solution is more complex. From the exploration of matter is ascertained that it is not connected with the conventional Leontief's model, but with an alternative exploitation of Ghosh's spin-offs. And besides, as Yamada (1961); Augusztinovics (1970); Jones (1976); Cronin (1984); Deman (1988); Adamou (2007); Kolokontes et al. (2019) had pointed out, the expansions, the prospects and the interpretations of emerged indicators from the Ghosh's directions are remain "open topics" in the literature. Furthermore, Yamada (1961); Augusztinovics (1970); Bayers (1976); Jones (1976); Cella (1984); Cronin (1984); Deman (1988); Dietzenbacher and Van Der Linden (1997); Cai and Leung (2004); Adamou (2007); A. H. Bekhet (2010); Ramos and Moreno (2013); Choi et al. (2014); Yasmin and Bekhet (2017) have agreed that cannot be determined the propulsive sectors of economy using exclusively data for the sectoral backward effects, ignoring the capability of sectors to generate forward impulses. This paper takes into account the pre-existed knowledge in order to build the theoretical and the practical basis for the utilization of idea for the "adjusted" forward-to-backward analysis.

Into this framework, the problem's statement as regards the dimensions about this topic is adduced as a first step. The I-O models are categorized using as criteria the direction for their analysis (backward-to-forward or forward-to-backward approach) and the fount of their stimuli (the changes on the components of intermediate and final demand vis-à-vis to them at the elements of intermediate and primary cost), aiming the specific positioning of "adjusted" forward approach among the I-O models. Continuing, the adjusted forward indicators (linkages indices and type I multipliers) are defined and compared with their corresponding non-adjusted traditional expressions, in order to be turned into comprehensible the distortions that are provoked at the estimation of multiplicative impacts and on the sectoral rankings when are used the non-adjusted indices. The necessity for the adjustment of forward indicators via the adjusted forward-to-backward approach as an obligatory complementary tool for a consummate developmental planning are corroborated through an empirical application, in the penultimate section. A synopsis of inferences concludes the paper.

\section{THE PROBLEM'S STATEMENT}

The causality of problem is found on the methods for the calculation of forward and backward indicators. The "quantitative Leontief's demand-driven model", scilicet the 
"quantitative backward-to-forward approach", is broadly applied in the literature both for the measurement of backloading and frontloading repercussions, and of course this is a false tactic because of the particular conceptual, computable and deterministic architecture of model. The caution can be done comprehensible when someone concentrated on the prerequisite and equal to the one unit conversion for the magnitudes of sectoral outputs (=unitary production's and allocation's functions), as below.

Specifically, the vertical sums of production's functions per sector $i(i=1,2, \ldots, n)$ in the productive network (=purchasers'view), are defined as:

$$
X^{\prime}=i^{\prime} Z+i^{\prime} V=i^{\prime} A<X>+i^{\prime} V_{c}<X>
$$

in which: $X=\left[X_{i}\right]$ is the vector of sectoral outputs; the symbol " $<>$ " denotes a vector's conversion to a diagonal matrix; "i" indicates a vector with all its elements to be equal to one; $V=\left[V_{i}\right]$ is the vector of primary inputs or else the value added vector; the $V_{c}=\left[V_{i} / X_{i}\right]$ signifies the value-added coefficients vector; and the tones indicate row-vectors (Leontief, 1936b, 1936a, 1937, 1941, 1944, 1947, 1951, 1986; de Mesnard, 2004; Dietzenbacher, 2005; Adamou, 2007; Tadayuki, 2008, pp. 40-54; Miller and Blair, 2009, pp. 3, 13; Sancho, 2012, 2013; Escaith, 2014; Okamoto, 2014; Soklis, 2014; Aroche Reyes and Marquez Mendoza, 2015; Jahn, 2015; Kelly, 2015; Imansyah et al., 2017; Muchdie et al., 2018; Trinh and Thai, 2021).

At the same time, the horizontal sums of allocation's functions per sector $\mathrm{i}(\mathrm{i}=1,2, \ldots, \mathrm{n})$ (=sellers' view), must be counted as:

$$
X=Z i+Y i=A<X>i+<X>Y_{c} i
$$

in which: $Y=\left[Y_{i}\right]$ is the vector of final demand; and the $Y_{c}=\left[Y_{i} / X_{i}\right]$ indicates the finaldemand coefficients vector.

Applying the backward-to-forward approach, behind from the equation (1), for $X_{i}=1$, via the "inputs coefficients", the production's functions reveal the dependency of each one purchaser-sector $\mathrm{i}(\mathrm{i}=1,2, \ldots, \mathrm{n})$ from their supplier-sectors and the primary productive factors that are used from the sector $\mathrm{i}$ in order to achieve its output (Leontief, 1936b, 1937, 1941, 1944, 1947, 1951, 1986; Oosterhaven et al., 2001; de Mesnard, 2004; Dietzenbacher, 2005; Tadayuki, 2008, pp. 40-54; Miller and Blair, 2009, pp. 3, 13, 16, 21; Sancho, 2012, 2013; Choi et al., 2014; Aroche Reyes and Marquez Mendoza, 2015; Jahn, 2015; Kelly, 2015; Kolokontes et al., 2019, 2020; Yotopoulos and Nugent, 1973):

$$
\sum_{j=1}^{n} a_{j i}+\left(w_{i}+p r_{i}+o_{i}+s_{i}^{g}+i m_{i}\right)=1 \Leftrightarrow V c_{i}+\sum_{j=1}^{n} a_{j i}=1
$$

in which: $w_{i}$ denotes the sectoral wages and salaries (household's income), $p r_{i}$ is the fee of entrepreneurship in the case of sector i, $o_{i}$ reflects the accumulated fees for the rest productive factors, $s_{i}^{g}$ is the pure taxes revenue that the government gains from the operation of sector $\mathrm{i}$ 
(as an abstraction between its direct-indirect taxes and its allowances) and $i m_{i}$ expresses the sectoral imports.

On contrast, from the side of output's distribution per seller-sector $i(i=1,2, \ldots, n)$ to the rest producers-sectors of economy and to the components of final demand, the allocation's functions that are generated from the backward-to-forward approach take the form (Kolokontes et al., 2019):

$$
\left.\sum_{j=1}^{n} a_{i j}+\left(c_{i}+g_{i}+i_{i}+e x_{i}\right) \neq 1 \Leftrightarrow Y c_{i}+\sum_{j=1}^{n} a_{i j} \neq 1 \text { (either }>1, \text { or }<1\right)
$$

in which: $c_{i}$ indicates the households' consumption for the sector's $\mathrm{i}$ output, $g_{i}$ is the governmental spending for the consumption of sector's i output, $i_{i}$ expresses the exploitation of output $\mathrm{i}$ for investments and $e x_{i}$ signifies the sectoral exports.

From the above is emerged the root for the examined problem which is the fact that in the quantitative backward-to-forward consideration (=quantitative Leontief's demand-driven model) the equation (4) is not tantamount to the one unit $(=1)$. This means that in this approach, the feature: $X_{i}=1$, is only in force for the columns' aggregations (=backward consideration) and it is violated into the rows' adds (=forward consideration) (Kolokontes et $a l ., 2019)$. With other words, due to the fact that the coefficients $a_{j i}$ of Leontief's technical coefficients matrix $A^{L}$ (=the superscript "L" denotes the origin from the Leontief's model) are generated from the backloading consideration of production's functions per each one sector $\mathrm{i}(\mathrm{i}=1,2, \ldots, \mathrm{n})$; following the conversion to the one unit for the gross value of sectoral output $X_{i}(=1)$; a produced consequence is the violation of this unitary consideration in this case in which someone attempt to sum horizontally the individual indices of backward-toforward approach (which is more often referring in the literature just as "backward" approach) from the traditional $A^{L}$ matrix with the sectoral technical coefficients of final demand (Kolokontes et al., 2019). Hence, among the vertical and the horizontal sums is valid the difference:

$$
\left(w_{i}+p r_{i}+o_{i}+s_{i}^{g}+i m_{i}\right) \neq\left(c_{i}+g_{i}+i_{i}+e x_{i}\right), \forall \mathrm{i}=1,2, \ldots, \mathrm{n}
$$

Similar but reverse deductions arise through the forward-to-backward approach, in which be in force that:

$$
\sum_{j=1}^{n} a_{j i}+\left(w_{i}+p r_{i}+o_{i}+s_{i}^{g}+i m_{i}\right) \neq 1 \Leftrightarrow V c_{i}+\sum_{j=1}^{n} a_{j i} \neq 1 \text { (either>1, or <1) }
$$




$$
\sum_{j=1}^{n} a_{i j}+\left(c_{i}+g_{i}+i_{i}+e x_{i}\right)=1 \Leftrightarrow Y c_{i}+\sum_{j=1}^{n} a_{i j}=1
$$

and thereafter be valid the equation (5), too.

Thus, either following the backward-to-forward approach, or the forward-to-backward one, is given that, in each case, the one from the two discussed sums (either the horizontal, or the vertical) will infract the unitary presupposition. Moreover, in any case:

$$
V A_{i} \neq Y_{i}, \forall \mathrm{i}=1,2, \ldots, \mathrm{n}
$$

although the fact that:

$$
\begin{gathered}
V_{i}+\sum_{j=1}^{n} a_{j i} X_{i}=Y_{i}+\sum_{j=1}^{n} a_{i j} X_{i} \\
\text { and } \\
\sum_{i=1}^{n}\left(V_{i}+\sum_{i=1}^{n} \sum_{j=1}^{n} a_{j i} X_{i}\right)=\sum_{i=1}^{n}\left(Y_{i}+\sum_{i=1}^{n} \sum_{j=1}^{n} a_{i j} X_{i}\right)
\end{gathered}
$$

something that implies the next inferences:

- $\mathrm{Ab}$ initio, according to its structural computable architecture, the "quantitative backward-to-forward Leontief's approach" is inappropriate for the derivation of sectoral direct and total forward linkages indicators and the subsequent type I and II forward multipliers (Augusztinovics, 1970; Bayers, 1976; Jones, 1976; Cai and Leung, 2004; A. H. Bekhet, 2010; Ramos and Moreno, 2013; Yasmin and Bekhet, 2017; Kolokontes et al., 2019). In other terms, the individual coefficients of backward-to-forward matrix $A^{L}$ that are used for the construction of inverse matrix $\left(I-A^{L}\right)^{-1}$ are lead to fallacious frontloading estimations for the significance of various sectors as regards their capability to ameliorate the future prosperity of economy (Cai and Leung, 2004; Kolokontes et al., 2019). Of course, these forward measurements are deceitful to be included into the formation of anyone else index as a part of it, as well (see for example: Cella, 1984; Clements, 1990; Clements and Rossi, 1991; Sonis et al., 1995; Guo and Hewings, 2001; Temurshoev and Oosterhaven, 2014). Hence, the backward-to-forward approach must be restricted to estimate only the backloading impacts via the direct and total backward linkages indices and the type I and II backward multipliers (Hirschman, 1958, pp. 98-107; Yotopoulos and Nugent, 1973; Cella, 1984; Cuello et al., 1992; Dietzenbacher, 2002; Cai and Leung, 2004; Tadayuki, 2008, pp. 40-54, 85-87; Miller and Blair, 2009, pp. 245, 555-558; A. H. Bekhet, 2010, 2011; Ramos and Moreno, 2013; Temurshoev and Oosterhaven, 2014; Freytag and Fricke, 2017; Yasmin and Bekhet, 2017; Chuenchum et al., 2018).

- Instead of it, another analysis, a forward-to-backward approach is necessary for the estimation of frontloading effects and the completion of analysis for a productive network, adding the forward view to the congruent backward one of traditional backward-to-forward Leontief's approach (Augusztinovics, 1970; Jones, 1976; Klein and Glickman, 1977; Ball, 
1981; Cai and Leung, 2004; Adamou, 2007; A. H. Bekhet, 2010; Ramos and Moreno, 2013; Choi et al., 2014; Grassini, 2014; Yasmin and Bekhet, 2017). However, with the same as above vein, according to its definition, the "quantitative forward-to-backward approach" is respective unsuitable for the generation of sectoral direct and total backward linkages indicators and their corresponding type I and II backward multipliers. The search in the literature for studies that have used correct individual forward-to-backward indices, either intuitively or consciously, to calculate forward linkages indicators is disheartening. The studies of Augusztinovics (1970); A. H. Bekhet (2010); Ramos and Moreno (2013); Yasmin and Bekhet (2017); de Lima Almeida and de Freitas Balanco (2020) constitutes cases close to the examined "adjusted forward-to-backward approach".

- The sectoral value added is not obligatorily equivalent with the sectoral final demand (see: equation 8). The sectoral value added can be greater or smaller comparing with the value of corresponding sectoral final demand, and vise-versa.

- However, in any occasion, the total value of intermediate and primary inputs that a sector i uses for its productive process must be equal with the total value of its sectoral gross output (with or without the conversion of measurements to the unit of magnitudes), either this output is channelized to the intermediate demand, or it is canalized outright to the final demand (see: equation 9).

- And furthermore, by default, the total gross output of economy must be equal with its total value added (equation 10).

Recapitulating, misunderstandings and mismanagements of individual direct and total coefficients are registered in the literature. The fount of problem is emanated from the erroneous frontloading exploitation of coefficients matrices' data that are obtained by the quantitative backward-to-forward Leontief's approach (Choi et al., 2014). Simultaneously, the literature has interested for the price-oriented Leontief's approach and the price-oriented Ghosh' approach (de Mesnard, 2016) ignoring the construction of "adjusted quantitative forward-to-backward approach". It must be stressed that in essential neither Ghosh (1958) studied this approach, since she had exclusively concentrated on the price-oriented direction of forward-to-backward consideration, and the repercussions of governmental interventions in the operation of Leontief's model, or else on the produced inflationary pressures via the degree of free for the markets.

\section{THE POSITIONG OF ADJUSTED FORWARD APPROACH AMONG THE I- O MODELS}

The previous section argues in favor of the complementarity between the "adjusted" quantitative forward-to-backward approach and the traditional backward-to-forward quantitative consideration (Augusztinovics, 1970), stressing the necessity for the adjustment of forward indices. The present section is concentrated on the explicit categorization of I-O models and the positioning of "adjusted forward-to-backward approach" among them. The structural effects of models ("backward-to-forward" or "forward-to-backward") and the origins of stimuli ( "price-oriented" and "quantity-oriented", with endogenous or exogenous origins, into the various open or closed schemes) are the attributive parameters for the categorization of I-O models (Cronin, 1984; Deman, 1988; de Mesnard, 2002a). The sectors in the I-O models can be seen under different roles, either as sellers-sectors and purchasers- 
sectors, or as suppliers-sectors and producers-sectors. All the sectors in a productive network get dressed all these roles.

The A matrix of Ghosh's consideration indicates the allocation's coefficients that are derived dividing horizontally per sector its distributed output to the others sectors of economy and to the components of final demand (as numerator), with the total sectoral output (as denominator). This approach is known in the literature as forward Ghosh's consideration and $a b$ initio had been focused on the changes of cost and prices, coming from the value added factors and the intermediate inputs as primary exogenous or endogenous stimuli (Ghosh, 1958; Miyazawa, 1976, pp. 1-42; Klein and Glickman, 1977; Ball, 1981; Oosterhaven, 1988, 1989, 1996; Dietzenbacher, 1997; de Mesnard, 1999, 2000b, 2000a, 2002a; Oosterhaven and Stelder, 2008; de Mesnard, 2009; Guerra and Sancho, 2010; Grassini, 2014; Aroche Reyes and Marquez Mendoza, 2015; de Mesnard, 2016, 2019a; Kolokontes et al., 2019; Oosterhaven, 2019; Thai and Trinh, 2019; Thai et al., 2019, 2020). These changes of value of sectoral inputs and outputs are happened supposing that the quantities of transactions remain stable. Given that the whole of I-O analysis with its expansions and the created spin-offs is relied on the Leontief's model which is the capstone of Quesnay and Walras theoretical ideas, the Ghosh's approach entered another view for the forward consideration of Leontief's model but only as an allocation model suitable for the measurement of inflationary pressures (Ghosh, 1958; Augusztinovics, 1970; Jones, 1976; Klein and Glickman, 1977; Ball, 1981; Oosterhaven, 1988; Gruver, 1989; Oosterhaven, 1996; Dietzenbacher, 1997; Oosterhaven et al., 2001; Dietzenbacher, 2002; Eiser and Roberts, 2002; Oosterhaven and Stelder, 2002; Cai and Leung, 2004; Polenske, 2004; Oosterhaven and Stelder, 2008; de Mesnard, 2009; Miller and Blair, 2009, pp. 543-555; Guerra and Sancho, 2010; Grassini, 2014; Temurshoev and Oosterhaven, 2014; Aroche Reyes and Marquez Mendoza, 2015; de Mesnard, 2016; Kelly et al., 2016; Freytag and Fricke, 2017; Oosterhaven, 2017; Kolokontes et al., 2019; Oosterhaven, 2019; Thai and Trinh, 2019; Thai et al., 2020). Let's mark the matrices of individual direct and total impacts' coefficients, that are obtained from the forward-tobackward consideration, as: $A^{G}$ and $\left(I-A^{G}\right)$.

From the other hand, in the "demand-driven Leontief's models", the A matrix represent the technical coefficients that are extracted per sector dividing vertically its primary and intermediate inputs (as numerator), and its sectoral output (as denominator), a methodology known in the literature as backward approach (Leontief, 1936b, 1936a, 1937, 1941, 1944, 1947, 1951; Leontief and Strout, 1963; Yotopoulos and Nugent, 1973; Leontief, 1986; Oosterhaven, 1996; de Mesnard, 1999, 2000b, 2004; Dietzenbacher, 2005; Meng et al., 2006; Oosterhaven and Stelder, 2008; Miller and Blair, 2009, pp. 16, 21; A. H. Bekhet, 2011; Sancho, 2012; Humavindu and Stage, 2013; Sancho, 2013; Grassini, 2014; de Mesnard, 2016, 2019a; Kolokontes et al., 2019; Oosterhaven, 2019; Kolokontes et al., 2020). The backward approach is referred to the traditional produced I-O matrices that are emanated from the classic Leontief's model. The matrices of backward-to-forward individual direct and total impacts' coefficients, had already marked as: $A^{L}$ and $\left(I-A^{L}\right)$. This matrices have been used either for analysis with stable prices and altering quantities by quantity-oriented endogenous or exogenous stimuli on the components of intermediate and final demand, or for analysis with stable quantities and changing cost and prices due to cost-push endogenous or exogenous stimuli on the intermediate and the value added productive factors (Pham et al., 2007; Kolokontes and Chatzitheodoridis, 2008; Kolokontes et al., 2008; Trinh et al., 2012; Choi et 
al., 2014; Escaith, 2014; Soklis, 2014; Trinh and Phong, 2014; Economakis et al., 2015; H. A. Bekhet et al., 2016; Imansyah et al., 2017; Kolokontes et al., 2018; Mariolis et al., 2018; Muchdie et al., 2018; Kolokontes et al., 2019; Mariolis et al., 2019; Teves, 2019; Thai and Trinh, 2019; Thai et al., 2019; Ferreira et al., 2020; Han et al., 2020; Kolokontes et al., 2020; Thai et al., 2020; Markaki and Economakis, 2021; Trinh and Thai, 2021).

Because of the two-fold dimension of transactions, is obvious that the baptized in the literature as "backward" approach is in essential a "backward-to-forward" approach, that can operate either as a "quantity-driven" or as a "price-driven" (or "cost-driven") consideration, as regards its impulses and the corresponding influences in the productive circuit (Augusztinovics, 1970; Yotopoulos and Nugent, 1973; Pham et al., 2007; Mariolis et al., 2018; Kolokontes et al., 2019; Mariolis et al., 2019). The same must be in force for the "forward" approach, which as a matter of fact is a "forward-to-backward" consideration, capable to operate as "quantity-driven" or as a "price-driven" (or "cost-driven"), as for its stimuli and the relevant spillovers in the productive network. This means that remains neglected the "quantity-driven approach of forward-to-backward analysis", that can be based on the primary stimuli that are accrued from the changes on the intermediate and final demand components (endogenously and exogenously), but under a distributional view. In any case, it must be commented that the distinction between "quantity-driven" and "price-driven" models according to their stimuli, is much better against to the bibliographical separation of models as "demand-driven" and "supply-driven", due to the fact that the demand and the supply phenomena coexist in all the versions of I-O models and not only in some of them, and furthermore the stimuli can be emanated, exogenous or endogenous, either from the intermediate and final demand factors, or from the intermediate and value added factors (Yotopoulos and Nugent, 1973; Miyazawa, 1976, pp. 1-42; Klein and Glickman, 1977; Choi et al., 2014; Grassini, 2014; de Mesnard, 2016). Consequently, at the cases in which the stimuli are registered, endogenously and exogenously, on the prices of intermediate and primary (=value added) inputs, the models are price-oriented, either its causality is backwardto-forward (="price-oriented Leontief's model") or it is forward-to-backward (="classic inflationary Ghosh's model"); while on the contrary, when the exogenous and endogenous stimuli are come from the changes on the requested quantities of intermediate and final demand, then the models are quantity-oriented, either its causality is backward-to-forward (= "classic quantitative Leontief"s demand-driven model"), or it is forward-to-backward (=the positioning of "adjusted quantitative forward-to-backward approach"), as well (Leontief, 1936b, 1936a, 1937, 1941, 1944, 1947, 1951, 1953; Ghosh, 1958; Leontief, 1961; Leontief and Strout, 1963; Augusztinovics, 1970; Leontief, 1971, 1974; Jones, 1976; Miyazawa, 1976, pp. 1-42; Cronin, 1984; Leontief, 1986; Deman, 1988; Oosterhaven, 1988; Baumol and Wolff, 1994; Oosterhaven, 1996; Dietzenbacher, 1997, 2001; Oosterhaven et al., 2001; de Mesnard, 2002b, 2002a; Dietzenbacher, 2002; Eiser and Roberts, 2002; Cai and Leung, 2004; de Mesnard, 2004; Oosterhaven and Stelder, 2008; de Mesnard, 2009; Miller and Blair, 2009, pp. 41-54, 543-555; A. H. Bekhet, 2010; Guerra and Sancho, 2010; A. H. Bekhet, 2011; Pnevmatikos et al., 2013; Ramos and Moreno, 2013; Sancho, 2013; Grassini, 2014; Soklis, 2014; Temurshoev and Oosterhaven, 2014; Aroche Reyes and Marquez Mendoza, 2015; Kelly, 2015; de Mesnard, 2016; A. H. Bekhet and Yasmin, 2017; Oosterhaven, 2017; Yasmin and Bekhet, 2017; Giannakis and Mamuneas, 2018; de Mesnard, 2019b, 2019a; Kolokontes et al., 2019; Oosterhaven, 2019; Thai and Trinh, 2019; de Lima Almeida and de Freitas 
Balanco, 2020; Ferreira et al., 2020; Hung et al., 2020; Kolokontes et al., 2020; Mariolis and Soklis, 2020; Trinh, 2020).

Another matter that must be clarified, regards the use in the literature of term "concentrated" effects for the forward-to-backward impacts (A. H. Bekhet, 2010; Ramos and Moreno, 2013; Kolokontes et al., 2019). However this term is abstruse since calls to the mind the whole influences on a sector's i output, intra-sectoral produced and inter-sectoral generated. Despite of the fact that there is the appropriate manner for the exclusive measure of concentrated repercussions on a specific sector's i output from the modifications (quantitative or inflationary) into the rest sectors of economy (either through the Leontief's paths, or via the Ghosh's paths), it must be unequivocal that the real scope of "forward-to-backward" approach are not to compute these "concentrated" sectoral influences themselves, but the measurement of diffused spillovers for the support of whole of sectoral outputs in the productive network, via the allocation's (or distribution's) functions that correspond to each one sector. Whereas, the "backward-to-forward" approach counts the dispersed effects to the rest sectors of economy individually and as a whole, via the production's functions of each one sector that operate as a propulsive factor into the feedback framework of its aim to increase its own output. Hence, the main scope for both these approaches is to estimate the repercussions to the other sectors of economy and not to count the concentrated effects. So, these must be kept in the mind is that at the backward consideration the effects into the nexus of whole of sectoral outputs are provoked due to an attempt from a specific sector i to produce its output, while at the forward approach the impacts at the whole of sectors of productive network are stemmed from the sector's i trial to sustain the outputs of other sectors (Grassini, 2014).

Diachronically, among others researchers and studies, taking into consideration: Leontief (1936b, 1936a, 1937, 1941, 1944, 1947, 1951, 1953, 1961, 1971, 1974, 1986, 1991), Yamada (1961), Ghosh (1958), Hirschman (1958, pp. 98-107), Augusztinovics (1970), Yotopoulos and Nugent (1973), F Giarratani (1976), Jensen (1976, pp. 39-48), Carroll (1980, pp. 5-10), F. Giarratani (1980), Cella (1984), Cronin (1984), Bon (1986); Deman (1988); Oosterhaven (1988); Gruver (1989); Oosterhaven (1989); Bon and Bing (1993); Bon and Yashiro (1996); Oosterhaven (1996); Dietzenbacher (1997); de Mesnard (1999, 2000b, 2000a); Dietzenbacher (2001); Oosterhaven et al. (2001); de Mesnard (2002b, 2002a); Dietzenbacher (2002); Eiser and Roberts (2002); Cai and Leung (2004); de Mesnard (2004); Dietzenbacher (2005); Adamou (2007); Pham et al. (2007); Oosterhaven and Stelder (2008); Tadayuki (2008, pp. 40-54, 85-87); de Mesnard (2009); Miller and Blair (2009, pp. 16, 21 , 13-13, 543-558); A. H. Bekhet (2010); Guerra and Sancho (2010); A. H. Bekhet (2011); Belegri-Roboli et al. (2011a); Belegri-Roboli et al. (2011b); Hristu-Varsakelis et al. (2012); Sancho (2012); Trinh et al. (2012); Humavindu and Stage (2013); Ramos and Moreno (2013); Sancho (2013); Choi et al. (2014); Escaith (2014); Grassini (2014); Okamoto (2014); Temurshoev and Oosterhaven (2014); Trinh and Phong (2014); Aroche Reyes and Marquez Mendoza (2015); Economakis et al. (2015); Jahn (2015); Kelly (2015); H. A. Bekhet et al. (2016); Belegri-Roboli et al. (2016); de Mesnard (2016); Kelly et al. (2016); A. H. Bekhet and Yasmin (2017); Freytag and Fricke (2017); Imansyah et al. (2017); Oosterhaven (2017); Trinh (2017); Yasmin and Bekhet (2017); Mariolis et al. (2018); Muchdie et al. (2018); de Mesnard (2019b, 2019a); Kolokontes et al. (2019); Mariolis et al. (2019); Nhung et al. (2019b); Oosterhaven (2019); Thai and Trinh (2019); de Lima Almeida and de Freitas Balanco (2020); Ferreira et al. (2020); Hung et al. (2020); Kolokontes et al. (2020); Mariolis and Soklis (2020); Thai et al. (2020); Trinh (2020); Hastuti et al. (2021); Markaki and 
Economakis (2021); Trinh and Thai (2021), the Table no. 1 concludes and gathers the proposed categories for the I-O models according to their causalities. The symbols in the Table no. 1 are interpreted as in the previous, and moreover the superscript "adj" means "adjusted". The case IV of table determines the "adjusted forward approach" of Kolokontes et al. (2019). Some useful observations as for the information that can be connected with the Table no. 1 are the following:

- The model definition as "backward-to-forward" or as "forward-to-backward" points out its causality.

- The categorization of models as "demand-driven" and "supply-driven" is not identified by their exogenous or endogenous impulses, either on the prices or on the quantities of their inputs and outputs, but it is identified relied on the direction of divisions for the derivation of coefficients of matrix A ( $A^{L}$ or $A^{G}$, respevtively). However, the per column divisions represent the "backward-to-forward approach" (either "price-driven" or "quantity-driven"), while the per row divisions stand for the "forward-to-backward approach" ("price-driven" and "quantity-driven", too).

Table no. 1 - The Determination of I-O Models According to Their Causality and Direction

\begin{tabular}{|c|c|c|}
\hline & Quantity-driven models & Price-driven models \\
\hline 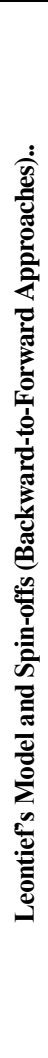 & $\begin{array}{l}\text { The quantity-driven backward-to-forward approach, } \\
\text { which is more known in the literature as the "quantity- } \\
\text { oriented Leontief's model" ("CASE I"): } \\
\text { The technical direct inputs coefficients or direct } \\
\text { requirements coefficients (=per column structure) are: } \\
\qquad A^{L}=\left[a_{j i}^{L}\right]=\left[Z_{j i} / X_{i}\right], \\
\text { and signify the direct coefficients of intermediate inputs, } \\
\text { that follow a change on the sector's i final demand, under } \\
\text { constant prices and variable quantities. } \\
\text { The technical coefficients matrix is determined as: } \\
\qquad A L=Z<X>-1 \\
\text { while the transactions matrix as: } \\
\qquad Z=A^{L}<X> \\
\text { The per sector total output vector is: } \\
\qquad X=Z i+Y=A^{L}<X>i+Y \\
\text { and the total non-inflationary purchases of intermediate } \\
\text { inputs, that are emerged owing to a change on the sector's } \\
\text { i final demand, and are diffused to the rest sectors of } \\
\text { economy, under constant prices and variable quantities, } \\
\text { are calculated as: } \\
\qquad d X=A^{L}<d X>i+d Y \\
\qquad \Rightarrow d X-A^{L}<d X>i=d Y \\
\qquad \Rightarrow d X-A^{L} d X=d Y \\
\qquad A X=\left(I-A^{L}\right) d X=d Y \\
\qquad A Y .\end{array}$ & 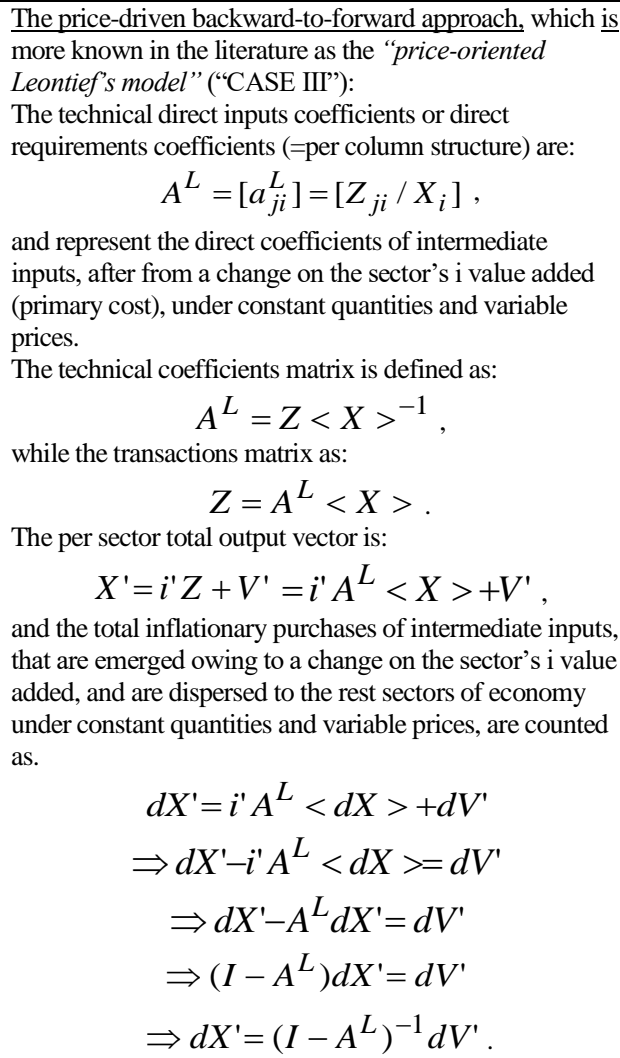 \\
\hline
\end{tabular}




\begin{tabular}{|c|c|c|}
\hline & Quantity-driven models & Price-driven models \\
\hline 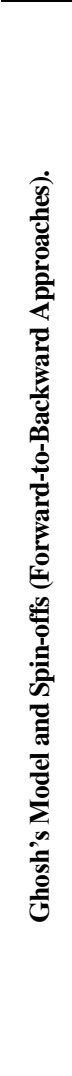 & 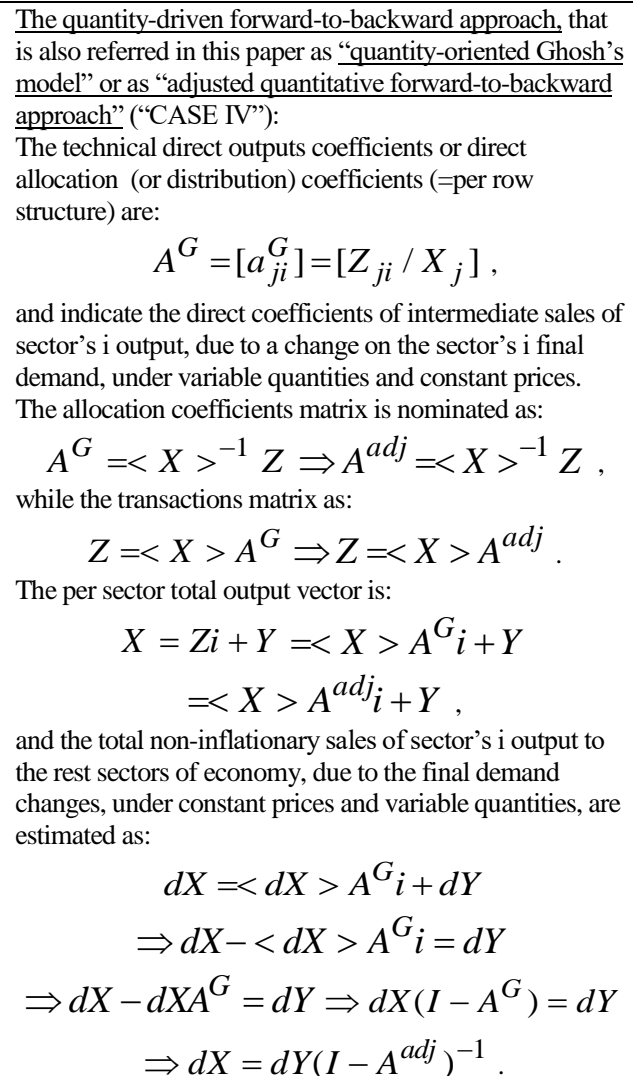 & $\begin{array}{l}\text { The price-driven forward-to-backward approach, which is } \\
\text { more known in the literature as 'price-oriented Ghosh's } \\
\text { model" ("CASE II"): } \\
\text { The technical direct outputs coefficients or direct } \\
\text { allocation (or distribution) coefficients (=per row } \\
\text { structure) are: } \\
\qquad A^{G}=\left[a_{j i}^{G}\right]=\left[Z_{j i} / X_{j}\right] \\
\text { and reflect the direct intermediate sales of sector's i } \\
\text { output, after from a change on the sector's i value added } \\
\text { (primary cost), under variable prices and constant } \\
\text { quantities. } \\
\text { The allocation coefficients matrix is defined as: } \\
\qquad A^{G}=<X>{ }^{-1} Z \\
\text { while the transactions matrix as: } \\
\qquad Z=<X>A^{G} \\
\text { The per sector total output vector is: } \\
\qquad X^{\prime}=i^{\prime} Z+V^{\prime}=i^{\prime}<X>A^{G}+V^{\prime}, \\
\text { and the total inflationary intermediate sales of sector's i } \\
\text { output to the rest sectors of economy, due to the value } \\
\text { added (primary cost) changes, under constant quantities } \\
\text { and variable prices, are computed as: } \\
\qquad d X^{\prime}=i^{\prime}<d X>A^{G}+d V^{\prime} \\
\qquad \Rightarrow d X^{\prime}-i^{\prime}<d X>A^{G}=d V^{\prime} \\
\qquad \Rightarrow d X^{\prime}-d X^{\prime} A^{G}=d V^{\prime} \\
\quad \Rightarrow d X^{\prime}\left(I-A^{G}\right)=d V^{\prime} \\
\Rightarrow d X^{\prime}=d V^{\prime}\left(I-A^{G}\right)^{-1}\end{array}$ \\
\hline
\end{tabular}

Source: author's process.

- Hence, the backward-to-forward consideration for the construction of direct technical coefficients matrix $A^{L}$ can be used for the estimation of diffused impacts either in a quantityoriented model (case I) or in a price-oriented model (case III).

- And also, the forward-to-backward approach for the construction of direct allocation coefficients matrix $A^{G}$ can be used for the measurement of dispersed effects either in a pricedriven model (cases II) or in a quantity-driven model (case IV).

- The case (I) is the static snapshot of interdependences among the sectoral production's functions and consequently depicts the offset point of present phase for the cross-sectoral balance, with standard the quantities and the prices (cost) in the sectoral productive processes (Leontief, 1951; Chen, 1976; Miller, 1989, p. 243; Briassoulis, 1991; Baumol and Wolff, 1994; Eiser and Roberts, 2002; Rickman, 2002; Pham et al., 2007; Meng et al., 2009; Miller and Blair, 2009, p. 243; Belegri-Roboli and Markaki, 2010; A. H. Bekhet, 2012; Trinh et al., 2012; Zhong and Tadayuki, 2013; Kelly, 2015; Mariolis et al., 2018; Kolokontes et al., 2019; Han et al., 2020; Mariolis and Soklis, 2020). Traditionally, the period with the standard prices (case I) is considered as a short-run time period (Jensen et al., 1979). 
- The case (II) is an ex post situation for the antecedent sectoral coherence of case (I) supposing variable prices and stable technologies for the production of each one sector, in a period with a length that is confined from the technical stability of sectoral production's functions. The transition from the case (I) to the case (II) signifies a static technicaltechnological period, with inflationary pressures, that can be corresponded to a transitive medium-run situation, before from the long-run period in which all the factors are variable (Almon, 1966; Chen, 1976; Carroll, 1980, pp. 12-16; Kuroda and Nomura, 2004; Trinh et al., 2012; de Mesnard, 2016). Kolokontes et al. (2019) have been illustrated the ex-ante to the expost connection that exists between the inflationary-pressures Ghosh's model and the traditional price-oriented Leontief's model, while de Mesnard (2013) had been explained the connection between the quantity-push and the price-push Leontief's models (cases I and III). The long-run timespan begins with the technical-technological modifications. In the long-run period can be happened all the kind of changes and this expresses a completely dynamic situation. However, due to the fact that the time-period for the technical-technological alterations for the sectoral productive processes differs from the one sector to another, the changes in only one sector suffice to indicate the offset for the dynamic phase of economy, since affect the operation of productive network as a whole. The alterations of sectoral production's functions certify the transitive to a dynamic situation, in which the sectoral primary and intermediate inputs and outputs are made over quantitative, qualitative, analogical or not, and in combination, because of simultaneous changes on the prices, the technologies and the qualities of inputs (Almon, 1966; Chen, 1976; Carroll, 1980, pp. 12-16; Rogerson and Plane, 1984; Plane and Rogerson, 1986; Miller, 1989; de Mesnard, 1990; Jackson et al., 1990; West, 1995; de Mesnard, 1997; Sonis and Hewings, 1998; de Mesnard, 2000a; Zhang, 2001; Ciobanu et al., 2004; Kuroda and Nomura, 2004; Lian and Haimes, 2006; Meng et al., 2009; Belegri-Roboli and Markaki, 2010; A. H. Bekhet, 2012; Baranov et al., 2014; Kelly, 2015; Han et al., 2020; Mariolis and Soklis, 2020).

- The model definition as "open", "close" and "how close", clarify the cases in which the components of final demand for the sectoral outputs operates as endogenous or exogenous variables for the model. The same is valid for the value added sectoral inputs (Leontief 1936a, 1937, 1944; Miyazawa, 1976, pp. 1-42; Bonfiglio, 2005, pp. 119-124; Grassini, 2014, Kolokontes et al., 2019). The intermediate demand for the sectoral outputs and the demand of intermediate inputs are clearly always endogenous into the models (Kolokontes et al., 2019).

- Furthermore, the demand of extra quantities for the intermediate and final inputs and outputs can be exclusively inflationary in these cases of individual sectors or for the whole of economy in which the productive factors (one or more) operate close or upon to their limits (Oosterhaven and Stelder, 2002). At these circumstances, following the locked proportions of Leontief's production's functions or of Ghosh's allocation's functions, the increase on a sector's i output can reduce other sectoral outputs, through the transition of suitable productive factors from the others to the sector's i productive process, and this signifies an opportunity cost for the evolution of economic welfare. This opportunity cost is concealed into the solely static I-O models of case (I), and it can be verified only using dynamic models or comparing static snapshots into the time (Oosterhaven and Stelder, 2002; Rogerson and Plane, 1984; Plane and Rogerson, 1986; Jackson et al., 1990; de Mesnard, 1990, 1997, 2000a; Ciobanu et al., 2004).

- The technological changes affect the production's functions, while the consuming changes alter the allocation's functions (Deman, 1988; Miller, 1989; Deman, 1991). 
- The structural changes affect both backward and forward, altering the production's functions and the allocation's functions too.

As it is obvious from the Table no. 1 , on the contrary to the $A^{L}$ matrix, the $A^{G}=A^{\text {adj }}$ matrix presents unitary sums for its rows and non-unitary sums for its columns. This means that the $A^{G}=A^{a d j}$ matrix is suitable for the forward analysis, but inappropriate for the backward analysis. Thereafter, the inverse matrix $\left(I-A^{G}\right)^{-1}=\left(I-A^{a d j}\right)^{-1}$ constitutes the base for the calculation of "adjusted" total forward linkages indicators and the corresponding type I and II forward multipliers.

The equation:

$$
X=Y\left(I-A^{a d j}\right)^{-1} \Rightarrow Y=X\left(I-A^{a d j}\right)
$$

represents the adjusted quantitative forward-to-backward analysis and it must not be confused:

-either with the equation:

$$
X=\left(I-A^{L}\right)^{-1} Y \Rightarrow Y=\left(I-A^{L}\right) X
$$

of quantitative backward-to-forward analysis,

-or with the equation:

$$
X^{\prime}=V^{\prime}\left(I-A^{G}\right)^{-1} \Rightarrow V^{\prime}=X^{\prime}\left(I-A^{G}\right)
$$

which is referred to the price-oriented forward-to-backward approach.

Many studies in the literature, even from wide-acceptable authors and researchers, either had used inapt measures for the appraisal of forward effects, or had accumulated backward and conventional (non-compatible) forward measures into fallible mixed indices (total or averages). For instance, among many others, the reader can look at wide-accepted and acclaimed authors and researchers as: Cella (1984), Clements (1990), Clements and Rossi (1991), Sonis et al. (1995), Sonis et al. (1996), Choi et al. (2014), Temurshoev and Oosterhaven (2014). Kolokontes et al. (2019) had pointed out that the accumulation of traditional non-compatible forward indicators with their backward mirrors infracts the rule of compatibility among the addend factors and furthermore enlarges the double-countings problem.

\section{THE ADJUSTED FORWARD INDICATORS.}

Following the descriptive notation of Kolokontes et al. (2019, 2020), in this section are nominated the fundamental equations of adjusted forward-to-backward approach for the computation of adjusted forward linkages indicators $\left[(a d j) F L s^{\prime}\right]$ and the relevant adjusted type I forward multipliers $\left[(a d j) t . I-F M s^{\prime}\right]$. In the next equations, the used symbols mean: In=Initial, $\mathrm{D}=$ Direct, $\mathrm{Ir}=$ Indirect, E=Effects. Particularly the term " $\operatorname{In} S E_{i}$ " is referred to the divisions $\left(S_{i} / \mathrm{X}_{i}\right)$ and expresses the "intra-sectoral initial trend for effects generation per 
kind $S$ " (or else: "the extra net per kind $S$ effect"). So, as $\langle\operatorname{In} S E>$ is denoted the diagonal matrix for the net sectoral propensity for impacts generation per each one controlled category "S" (Kolokontes et al., 2019, 2020).

For brevity's sake, the adopted factor "S" brings out any parameter for which can be checked the impacts measurements $[\mathrm{S}=\mathrm{O}$ (Output), $\mathrm{S}=\mathrm{E}$ (Employment), $\mathrm{S}=\mathrm{W}$ or I (Wages and Salaries or Income), and whatever else]. Under this vein: $(a d j) S D F L=(\operatorname{adj}) D F S E$ signifies the adjusted direct forward repercussions per factor "S"; $(a d j) S T F L=(a d j) \operatorname{InDIrFSE}$ signals the adjusted total (initial, direct and indirect) impacts per factor "S" into the whole of economy; $(\operatorname{adj}) \operatorname{TrSTFL}=(\operatorname{adj}) \operatorname{DrFSE}$ expresses the corresponding truncated (direct and indirect) influences, $(\operatorname{adj}) \operatorname{SIr} F L=(\operatorname{adj}) \operatorname{IrFSE}$ signifies the isolation of indirect per kind "S" effects; (adj)t.I - SFM denotes the adjusted total type I forward multiplier; (adj)t.I-DSFM symbolizes the adjusted direct type I forward multipliers; $(a d j) t . I-I r S F M$ presents the isolation of corresponding indirect effects; and $(a d j)[\operatorname{Tr}] t . I-S F M$ is the relevant truncated (direct and indirect) magnitude. For more details about the initial, direct and indirect influences and their combinations and definitions: specific for the particular case of output $(\mathrm{S}=\mathrm{O})$, but even more for anyone else kind " $\mathrm{S}$ " of measured effects, the reader can look at Kolokontes et al. (2019, 2020).

As (adj)SDM is symbolized the adjusted direct coefficients matrix per sector $\mathrm{S}$, and as (adj)STM the respective adjusted total coefficients matrix:

$$
(a d j) S D M=A^{a d j}<S><X>^{-1}=A^{a d j}<\operatorname{InSE}>, \text { with: } A^{a d j}=\left[a_{i j}^{a d j}\right]
$$

and:

$$
\begin{gathered}
(\text { adj }) S T M=\left(I-A^{a d j}\right)^{-1}<S><>^{-1}=\left(I-A^{a d j}\right)^{-1}<\operatorname{InSE}>= \\
B^{a d j}<\operatorname{InSE}> \\
\text { with: } B^{a d j}=\left(I-A^{a d j}\right)^{-1}=\left[b_{i j}^{a d j}\right]
\end{gathered}
$$

The vectors of adjusted direct and total forward linkages indicators per measured kind "S" of dispersed impacts [(adj)SDFLs',(adj)STFLs'] are calculated through the equations:

and:

$$
\begin{gathered}
(\text { adj }) S D F L=(\text { adj }) D F S E=[(\text { adj }) S D M] i=A^{a d j}<\text { InSE }>i= \\
A^{a d j}<S><X>^{-1} i
\end{gathered}
$$

$$
\begin{gathered}
(\text { adj }) S T F L=(\text { adj }) \operatorname{InDIrFSE}=[(\text { adj }) S T M] i= \\
\left(I-A^{a d j}\right)^{-1}<\operatorname{InSE}>i=\left(I-A^{a d j}\right)^{-1}<S><X>^{-1} i
\end{gathered}
$$

and moreover the truncated (direct and indirect) magnitude is: 


$$
\begin{gathered}
(\text { adj }) \operatorname{TrSTFL}=(\text { adj }) \text { DIrFSE }=(\text { adj }) \operatorname{InDIrFSE}-\operatorname{InSE}= \\
{[(\text { adj }) S T M] i-<\operatorname{InSE}>i=\left[\left(I-A^{\text {adj }}\right)^{-1}<\operatorname{InSE}>i\right]-(<\operatorname{InSE}>i)=} \\
{\left[\left(I-A^{a d j}\right)^{-1}<S><X>^{-1} i\right]-\left(<S><X>^{-1} i\right)}
\end{gathered}
$$

while the isolation of indirect effects is:

$$
\begin{gathered}
(\text { adj }) S I r F L=(\text { adj }) \operatorname{IrFSE}=(\text { adj }) \operatorname{InDIrFSE}-(\text { adj }) D F S E-\operatorname{InSE}= \\
{[(\text { adj }) S T M] i-[(\text { adj }) S D M] i-<\operatorname{InSE}>i=} \\
{\left[\left(I-A^{a d j}\right)^{-1}<\operatorname{InSE}>i\right]-\left(A^{a d j}<\operatorname{InSE}>i\right)-(<\operatorname{InSE}>i)=} \\
{\left[\left(I-A^{a d j}\right)^{-1}<S><X>^{-1} i\right]-\left(A^{a d j}<S><X>^{-1} i\right)-\left(<S><X>^{-1} i\right)}
\end{gathered}
$$

and these indices per sector $\mathrm{i}(\mathrm{i}=1,2, \ldots, \mathrm{n})$ are:

$$
\begin{aligned}
& (a d j) S D F L_{i}=(a d j) D F S E_{i}=\sum_{j=1}^{n} a_{i j}^{a d j} I n S E_{j} \\
& (\text { adj }) S T F L_{i}=(\text { adj }) \operatorname{InDIrFSE} E_{i}=\sum_{j=1}^{n} b_{i j}^{a d j} \operatorname{InSE} E_{j} \\
& (a d j) \operatorname{TrSFL} L_{i}=(a d j) D I r F S E_{i}=(a d j) S T F L_{i}-\operatorname{InSE} E_{i}=\left(\sum_{j=1}^{n} b_{i j}^{a d j} \operatorname{InSE} E_{j}\right)-\operatorname{InSE} E_{i} \\
& (a d j) S I r F L_{i}=(a d j) \operatorname{IrFSE} E_{i}=(a d j) S T F L_{i}-(a d j) S D F L_{i}-\operatorname{InSE} E_{i} \\
& =\left(\sum_{j=1}^{n} b_{i j}^{a d j} \operatorname{InS} E_{j}\right)-\left(\sum_{j=1}^{n} a_{i j}^{a d j} \operatorname{InSE} E_{j}\right)-\operatorname{InS} E_{i}
\end{aligned}
$$

At this point, it must be commented that Kolokontes et al. (2019) in their theoretical proposal for the adjusted forward approach had supposed as possible for the derivation of vector of adjusted total forward linkages indices the equation: $S T F L=\operatorname{InDIrFSE}$ $=[($ adj $) S T M] i=<\operatorname{InSE}>\left(I-A^{a d j}\right)^{-1} i=<S><X>^{-1}\left(I-A^{a d j}\right)^{-1} i$. In this paper the equations (14) : (27) are emerged after from the deductions of empirical applications and tests (see the example in the next section), as regards the examined proposal for the adjusted forward-to-backward consideration. The initial view of Kolokontes et al. (2019) for the premultiplication of vector $\left\langle\operatorname{InSE}>\right.$ with the adjusted inverse matrix $\left(I-A^{a d j}\right)^{-1}$ is explicit that it is not the appropriate form for the extraction of adjusted total forward linkages indicators, since the practice reveals that the post-multiplication of $\langle\operatorname{In} S E\rangle$ with the matrix $\left(I-A^{a d j}\right)^{-1}$ is ultimately the correct choice. Similarly, the equations: 
$S D F L_{j}=\sum_{i=1}^{n} a_{j i} I n S E_{j}$ and $S T F L_{j}=\sum_{i=1}^{n} b_{j i} I n S E_{j}$ are proved incorrect and must have the shape of equations (20) and (21).

It must be clarified, that the referring paper of Kolokontes et al. (2019) was not concentrated on the topic of adjusted forward approach itself, but among many other matters just had put it on the table as a problem for a future inquiry, offering potential expansions in order to "tease the curiosity of scholars, researchers, readers and policy-makers" (Kolokontes et al., 2019). Instead of it, in their paper Kolokontes et al. (2019) were basically focused on the Leontief's model, their spin-offs and indices, aiming to register the complications and the imprecisions in the literature among the used nomenclature and the computable applications in the case of conventional I-O models and their indicators, proposing solutions in many occasions that rationalize the connection between the indices and the terminologies, with an emphasis on the peculiarities of various indices (weighted or not) and their usefulness. However, the adjusted forward approach, as it has been clarified in the table 1 above, find its expression via the quantitative forward-to-backward approach, which could be regarded as the quantitative consideration of Ghosh's model.

In the framework of scientific evolution, historically differentiated models and indicators have decided, constructed, scrutinized and criticized for their outcomes according to their appropriateness for the developmental programming (Dietzenbacher, 2005; Sancho, 2013; Guang and Wen, 2020; Kolokontes et al., 2020). All of them have distributed something different or something more (Dietzenbacher, 2005), acceptable or rejected during the time, but in anyway noteworthy for the scientific progress (Kolokontes et al., 2020).

This paper has not as primary aim to define the propulsive sectors for a specific economic network, neither to adduce a complete backward and forward analysis both for an economy. Something like that will extremely expand it. Instead of these, the scope of paper is the foundation and the first technical exhibition of adjusted forward-to-backward approach using concrete data. After from the theoretical analysis, follows in the next section the numerical comparison among the adjusted and the non-adjusted forward linkages indices $\left[(a d j) F L s^{\prime}, F L s^{\prime}\right]$. The practical juxtaposition of obtained measurements using real data intends to help the readers to comprehend the emerged differences at the sectoral magnitudes of wide-economy multiplying impacts, along with the divergences on the classifications that these indices yield. The output and the income constitute the two factors that have been chosen for the measurements presentation, expressing the differentiated architecture as for its conceptual and computable causality. The causality's matter had been explained in detail at Kolokontes et al. (2019, 2020), in which they had thoroughly scrutinized and had elucidated the conceptual and the architectural connections among the causalities and the measurements of various indices per kind " $\mathrm{S}$ ". These causalities are in force both at the cases of backwardto-forward (B) and forward-to-backward (F) considerations. Hence, because of their enunciations the direct, the indirect, the truncated and the total type I multipliers of output (t.I - DOM ,t.I - IrOM , t.I - TrOM,t.I -OM) are identical to the direct, the indirect, the truncated and the total linkages indices (ODFL, OIrFL, TrOTFL, OTFL). However the same is not valid at the cases of other kinds " $\mathrm{S}$ " of measured effects (i.e. when: $\mathrm{S}=$ Employment, $\mathrm{S}=$ Income, e.t.c.) due to the heterogeneity between the sectoral initial exogenous stimuli and the relevant intrasectoral initial trends for effects generation per kind " $\mathrm{S}$ ".

The above mean that in the case of output be in force that: 


$$
\begin{gathered}
(\text { adj }) t . I-F O M=(\text { adj }) O T F L=(\text { adj }) \operatorname{InDIrFOE} \\
(\text { adj }) t . I-\text { TrFOM }=(\text { adj }) \operatorname{TrOTFL}=(\text { adj }) D I r F O E \\
(\text { adj }) t . I-F I r O M=(\text { adj }) \operatorname{TrOIrFL}=(\text { adj }) \operatorname{IrFOE} \\
(\text { adj }) t . I-F D O M=(\text { adj }) O D F L=(\text { adj }) D F O E
\end{gathered}
$$

while for any other factor "S", except from the output, is valid that:

$$
\begin{aligned}
& (\text { adj)t.I }-F S M \neq(\text { adj }) S T F L \Rightarrow(\text { adj }) t . I-F S M \neq(\text { adj }) \operatorname{InDIrFSE} \\
& \text { (adj)t.I }-\operatorname{TrFSM} \neq(\text { adj)TrSTFL } \Rightarrow \text { (adj)t.I }-\operatorname{TrFSM} \neq(\text { adj)DIrFSE } \\
& \text { (adj)t.I }- \text { FIrSM } \neq(\text { adj)SIrFL } \Rightarrow \text { (adj)t.I. }- \text { FIrSM } \neq(\text { adj)IrFSE } \\
& \text { (adj)t.I }-F D S M \neq(\text { adj) SDFL } \Rightarrow(\text { adj)t.I }-F D S M \neq(\text { adj)DFSE }
\end{aligned}
$$

scilicet the magnitudes and the classifications from the direct, the indirect, the truncated and the total type I "S-kind" multipliers for each one sector i are not in consonance with the relative measurements and rankings that are obtained by the linkages indicators, with the exception of output's case.

Furthermore, Kolokontes et al. (2020) delving at the conceptual and computational roots of various indices as for their peculiarities and usefulness, had declared and expounded the superiority of type I backward multipliers $\left(t . I-B M s^{\prime}\right)$ for the medium-to-long run growing planning against to the tendentious backward linkages indices $\left(B L s^{\prime}\right)$, applying a decomposition analysis for their synthetic components. Because of their conceptual architecture, as the readers can see in the tables of next section, the forward linkages indices keep the same inequitable characteristics of their backward mirrors, but however are necessary as the intermediate guides for the forthcoming generation of adjusted type I forward multipliers [(adj)t.I - FMs'] .

For the sake of generality, following the reformation of $\operatorname{InSE} E_{i}$ from less than one $(<1)$ to a reformed measurement that will be equal to one $(=1)(\mathrm{r}=$ reformed), via the revealed reformations of forward linkages indices, finally the vectors of adjusted total, direct, indirect and truncated type I forward multipliers per kind "S" (t.I-FSM, t.I-FDSM, t.I - FIrSM , t.I - TrFSM ) can be defined as:

$$
\begin{gathered}
t . I-F S M=\left[\left(I-A^{a d j}\right)^{-1}\left(<S><X>^{-1} i\right)\right]\left(<S><>^{-1} i\right)^{-1} \\
=\left[\left(I-A^{a d j}\right)^{-1}<\operatorname{InSE}>i\right](<\operatorname{InSE}>i)^{-1}=[[(\text { adj }) S T M] i](<\operatorname{InSE}>i)^{-1} \\
=\operatorname{InDIrFSE}(<\operatorname{InSE}>i)^{-1}=\operatorname{rInDIrFSE} \\
t . I-D F S M=\left[A^{\text {adj }}\left(<S><>^{-1} i\right)\right]\left(<S><>^{-1} i\right)^{-1} \\
=\left(A^{\text {adj }}<\operatorname{InSE}>i\right)(<\operatorname{InSE}>i)^{-1}=[[(\text { adj }) S D M] i](<\operatorname{InSE}>i)^{-1} \\
=\operatorname{DFSE}(<\operatorname{InSE}>i)^{-1}=r D F S E
\end{gathered}
$$




$$
\begin{aligned}
t . I-\operatorname{IrFSM}= & (t . I-F S M)-(t . I-D F S M)-\operatorname{InSE}=(t . I-F S M)-(t . I-D F S M)-i \\
& t . I-\operatorname{Tr} F S M=(t . I-F S M)-\operatorname{InSE}=(t . I-F S M)-i
\end{aligned}
$$

while per sector $\mathrm{i}$ :

$$
\begin{aligned}
& t . I-F S M_{i}=\frac{r \operatorname{rnDIrFSE} E_{i}}{r \operatorname{InSE} E_{i}}=\frac{\left(\operatorname{InDIrFSE} E_{i} / \operatorname{InSE} E_{i}\right)}{r \operatorname{InS} E_{i}}=\frac{r \sum_{j=1}^{n} b_{i j}^{(a d j)} \operatorname{InSE} E_{j}}{r \operatorname{InS} E_{i}} \\
& =\frac{r \sum_{j=1}^{n} b_{i j}^{(a d j)} \operatorname{InSE} E_{j}}{1}=r \sum_{j=1}^{n} b_{i j}^{(a d j)} \operatorname{In} S E_{j} \\
& \text { (in which: } r \sum_{j=1}^{n} b_{i j}^{(a d j)} \operatorname{InSE} E_{j} \neq \sum_{j=1}^{n} b_{i j}^{(a d j)} \operatorname{InSE} E_{j} \text { ) } \\
& t . I-D F S M_{i}=\frac{r D F S E_{i}}{r \operatorname{InSE} E_{i}}=\frac{\left(D F S E_{i} / \operatorname{InSE} E_{i}\right)}{r \operatorname{rnS} E_{i}}=\frac{r \sum_{j=1}^{n} a_{i j}^{(a d j)} \operatorname{InS} E_{j}}{r \operatorname{InSE} E_{i}} \\
& =\frac{r \sum_{j=1}^{n} a_{i j}^{(a d j)} \operatorname{InSE} E_{j}}{1}=r \sum_{j=1}^{n} a_{i j}^{(a d j)} \operatorname{InS} E_{j} \\
& \text { (in which: } r \sum_{j=1}^{n} a_{i j}^{(a d j)} \operatorname{InSE} E_{j} \neq \sum_{j=1}^{n} a_{i j}^{(a d j)} \operatorname{InSE} E_{j} \text { ) } \\
& \text { t.I }-\operatorname{IrFSM}_{i}=\left(t . I-F S M_{i}\right)-\left(t . I-\operatorname{DFSM}_{i}\right)-1 \\
& \text { t.I }-\operatorname{TrFSM}_{i}=\left(t . I-F S M_{i}\right)-1
\end{aligned}
$$

\section{DATA AND RESULTS}

The using data for the empirical analysis are emanated from the Greek symmetric I-O table of 2015 (64x64) (Hellenic Statistical Authority, 2019), which has been re-formed into a 59 sectors scheme for technical reasons. The following number of sectors is quite analytical so as to be more visible and emphatic the divergences of magnitudes and rankings per sector and among the various indices, without possible distortions and convergences owing to excessive sectoral aggregations. 
Table no. 2 illustrates the logic behind from the necessity for the construction of adjusted direct forward linkages indicators for the sectoral outputs $\left[(a d j) O D F L s^{\prime}=(a d j) D F O E s^{\prime}\right]$. In the Table no. 2, the column [3] depicts the non-adjusted forward linkages indicators for the sectoral outputs as they are obtained from the backward-to-forward consideration. On the contrary, the adjustment of individual direct forward-to-backward transactions coefficients $\left(a_{j i}^{a d j}\right)$ builds the suitable direct forward-to-backward linkages indices for the sectoral outputs, that are registered in the column [4]: (adj)ODFL $L_{i}=(\operatorname{adj}) D F O E_{i}=\sum_{j=1}^{n} a_{i j}^{a d j}$. The column [5] shows the derived final demand coefficients $\left(Y c_{i}\right)$ that are common both for these two approaches. The accumulation of columns [3] and [5] creates the column [6], while the summation of columns [4] and [5] produces the column [7]. The readers can easily ascertain that the numbers of column [6] does not follow the rule of horizontal unitary add showing the value of sectoral gross output to be once greater and once less than the one $(>1,<1)$ : $X_{i}=\left(O D F L_{i}+Y c_{i}\right) \neq 1$, either $>1$, or $<1$. Instead of it, at the column [7] the sums are equal to one $(=1): X_{i}=\left[(a d j) O D F L_{i}+Y c_{i}\right]=1$. Hence, the results of Table no. 2 corroborate the necessity for the adjustment of forward measurements. By definition, the coefficients of column [3] that are met in the literature are incorrect, as well as all the "mixed" indices in which such non-adjusted forward magnitudes are accumulated with backward measurements. The adjusted sectoral forward linkages indicators of forward-to-backward approach of column [4] constitute the compatible and comparable magnitudes vis-à-vis to their corresponding backward considerations from the backward-to-forward approach. The sectoral short-cuts of column [1] are adopted into the next tables.

In addition, it must be clarified that the logical value range for the magnitudes of direct linkages indicators must belongs to $[0,1]$. This range is the same for the backward and the forward linkages indicators, too. The cases in which the non-adjusted ODFLs' are greater than one (>1) into the Table no. 2 (column: [3]) are owing to the distortions that are revealed from their fallacious backward-to-forward consideration for their construction (equation 4). Instead of them, the adjusted direct forward linkages indicators are complied with this restriction (equation 7), with an only one exception. The only case in which an adjusted direct forward linkages index could be out from the range $[0,1]$ and more specifically greater than one $(>1)$ is the extremely case in which the respective sectoral final demand coefficient is negative $(<0)$. This is an unusual situation that is originated from an accounting high negative value for the sector's stock $(<0)$ as a component part for the configuration of magnitude for the sectoral investment, which is so high that ends up to a negative sectoral investment $(<0)$ which exceeds the positive summation among the households' consumption, the governmental spending for consumption and the exports value for this sectoral output. A situation like this is recorded in the Table no. 2 at the case of sector D, in which the sectoral final demand coefficient is negative $(<0)$ (column: [5]) and this implies a greater than the one unit measurement of adjusted direct forward linkages index $(>1)$ (column: [4]), so that to become equal to one the value of sector's output (column: [7]). 


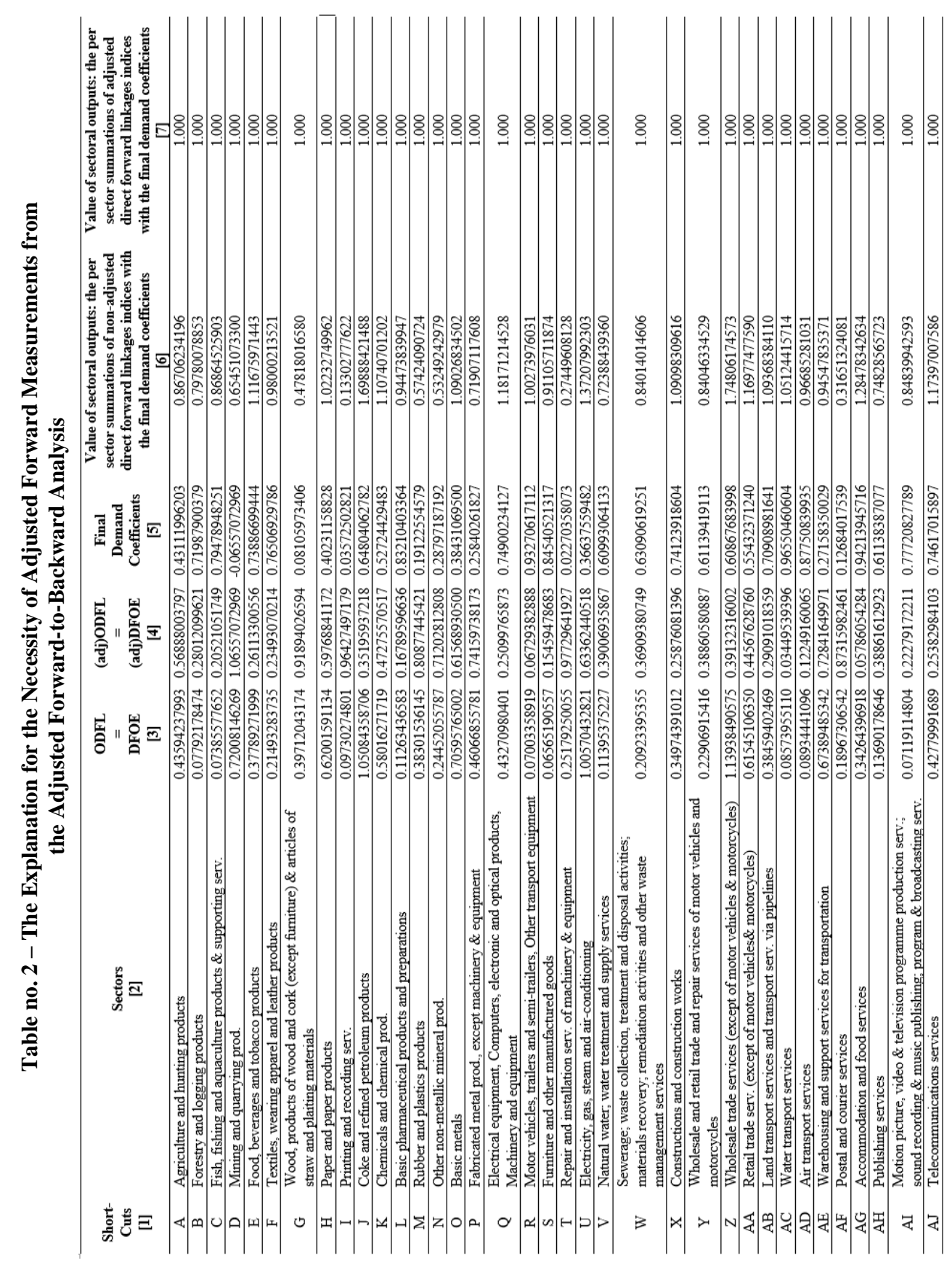




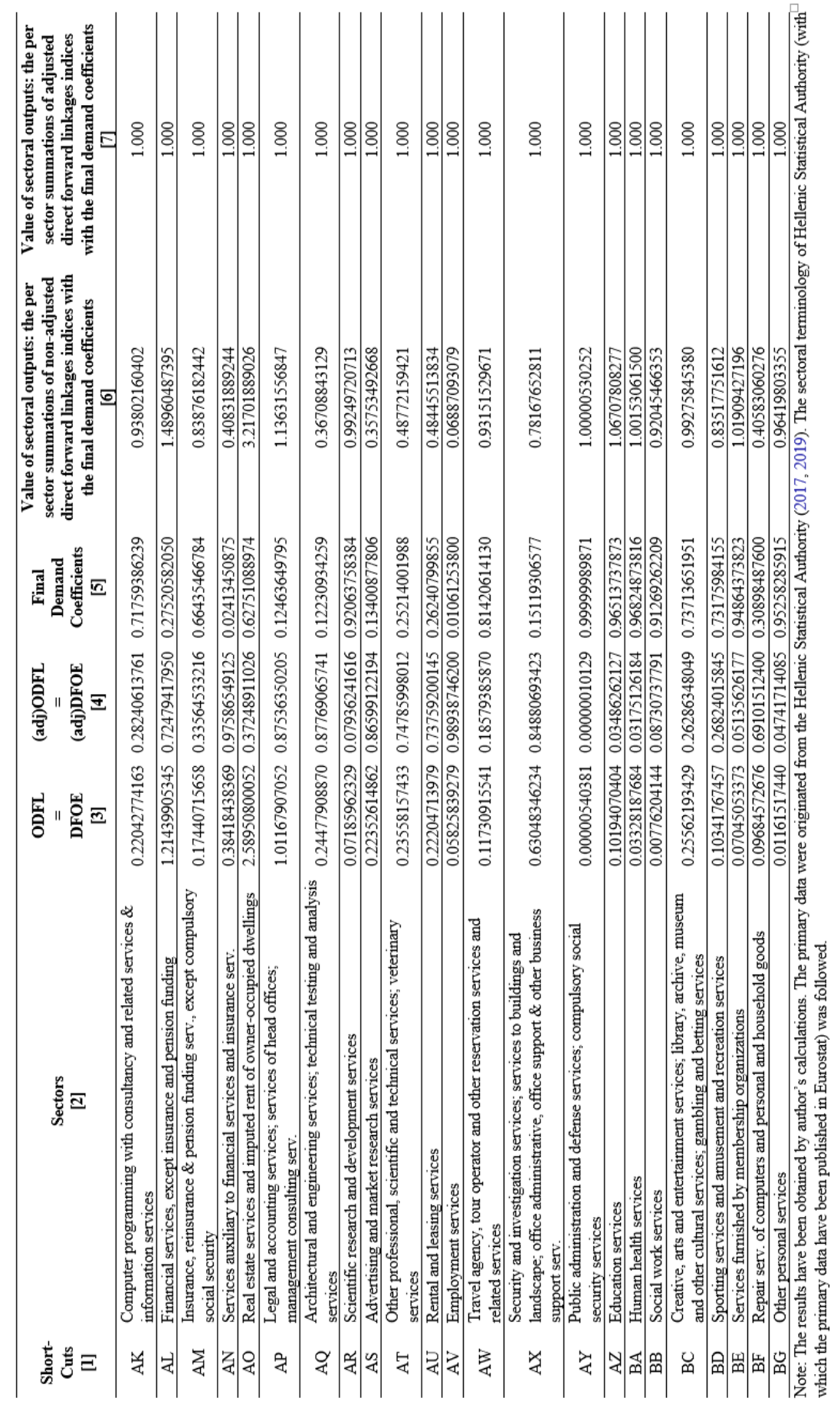


Something analogous can be happened in the backward-to-forward approach at this particular case in which a sector records a negative operational surplus (a pure loss) so high that ends up to a negative value added. However, there is no case in which an individual adjusted direct forward-to-backward coefficient $\left(a_{i j}^{a d j}\right)$ is possible to be negative, since by default: $a_{i j}^{a d j}>0, \forall i, j=1,2 \ldots, n$. The same of course is also in force in the backward-toforward consideration: $a_{j i}>0, \forall i, j=1,2 \ldots, n$.

The Table no. 3 portrays a decomposition analysis of adjusted and non-adjusted approach for the direct, indirect and total type I forward multipliers of output and the comparison for their magnitudes and their rankings. The total multiplicative influences are the summation of initial, direct and indirect effects. So, the initial intrasectoral trends for the generation of output effects are included into the magnitudes of total multiplicative impacts. The outcomes substantiate the differences among the measurements and the classifications of adjusted and the non-adjusted frontloading approaches. The non-adjusted forward approach is proved fallacious for the determination of forward-to-backward propulsive sectors.

As a matter of fact, among the more significant sectors, as for their potential ability to disperse multiplicative impacts in terms of generated gross output to the rest of economy, using as criterion the adjusted total type I forward output multipliers [ (adj)t.I - FOM ], are: the employment services (AV: 2.72809, 1st), the mining and quarrying products (D: 2.69555 , 2nd), the wood products (G: 2.61299, 3rd), the auxiliary financial services (AN: 2.57746, 4 th), the legal and accounting services (AP: 2.42566 , 5th), the repair and installation services of machinery and equipment (T: $2.42280,6$ th), the courier services (AF: $2.38005,7$ th), the rubber and plastic products (M: 2.29862, 8th), the advertising and market research services (AS: $2.28155,9$ th), and the printing and recording services (I: $2.23375,10$ th). Whereas, at the same time the corresponding non-adjusted index [t.I-FOM ] marks as more important frontloading sectors for the Greek productive network: the real-estate services (AO: 5.16268, $1 \mathrm{st}$ ), the financial services (AL: 2.81707, 2nd), the mining and quarrying products (D: $2.76463,3 \mathrm{rd})$, the wholesale trade services ( $\mathrm{Z}: 2.75619,4 \mathrm{th})$, the coke and refined petroleum products (J: 2.65737, 5th), the legal accounting services (AP: 2.57047 , 6th), the electricity and gas (U: 2.47461, 7th), the basic metals (O: 2.24459, 8th), the warehousing and support services for transportation (AE: 1.97823, 9th), and the paper products (H: 1.95299, 10th). However, some of the latter sectors are not really suitable for frontloading spillovers on the economy's gross output, as it is proved from their adjusted measurements and rankings. Of course, as someone can observes the differences among the adjusted and the non-adjusted outcomes are not identified only by the sectoral classifications, but are recorded on the estimation of various magnitudes, as well. As it has been explained earlier, the scope of paper is not to provide a complete backward-to-forward and forward-to-backward analysis for the Greek economy, but the presentation of adjusted forward-to-backward approach. For this reason, the complete analysis with its comments for the Greek economy remains an open topic for a future study, in which will be married the estimations for the wide-economy dispersed influences both via the forward and the backward type I multipliers. 
Table no. 3 - The Comparison Among the Magnitudes and the Rankings of Direct, Indirect and Total Type I Forward Output Multipliers from the Adjusted and the Non-Adjusted Approach [t.I-DFOM, (adj)t.I-DFOM, t.I-IrFOM, (adj)t.I-IrFOM, t.I-FOM, (adj)t.I-FOM]

\begin{tabular}{|c|c|c|c|c|c|c|}
\hline $\begin{array}{l}\text { ectors } \\
{[1]}\end{array}$ & $\begin{aligned} & \text { ODFL } \\
&= \text { t.I-DFON } \\
& {[2] }\end{aligned}$ & $\begin{aligned} &(\text { adj)ODFL } \\
&=(\text { adj)t.I-DFOM } \\
& {[3] }\end{aligned}$ & $\begin{aligned} & \text { OIrFL } \\
&= \text { t.I-IrFOM } \\
& {[4] }\end{aligned}$ & $\begin{aligned} &(\text { adj)OIrFL } \\
&=(\text { adj)t.I-IrFOM } \\
& {[5] }\end{aligned}$ & $\begin{aligned} & \text { OTFL } \\
= & \text { t.I-FOM } \\
& {[6] }\end{aligned}$ & $\begin{aligned} &(\text { adj)OTFL } \\
&=(\text { adj)t.I-FOM } \\
& {[7] }\end{aligned}$ \\
\hline A & $0.43594(15)$ & $0.56888(23)$ & $1.22470(16)$ & $1.22964(24)$ & $1.66064(15)$ & $1.79852(23)$ \\
\hline B & $0.07792(48)$ & $0.28012(36)$ & $1.01611(50)$ & $1.18827(31)$ & $1.09404(49)$ & $1.46839(35)$ \\
\hline $\mathrm{C}$ & $0.07386(49)$ & $0.20521(45)$ & $1.00892(54)$ & $1.03629(47)$ & $1.08277(52)$ & $1.24150(45)$ \\
\hline $\mathrm{D}$ & $0.72008(07)$ & $1.06557(01)$ & $2.04455(02)$ & $1.62998(03)$ & $2.76463(03)$ & $2.69555(02)$ \\
\hline $\mathrm{E}$ & $0.37789(22)$ & $0.26113(39)$ & $1.15492(22)$ & $1.05469(45)$ & $1.53282(22)$ & $1.31582(44)$ \\
\hline $\mathrm{F}$ & $0.21493(34)$ & $0.23493(43)$ & $1.10830(25)$ & & $1.32324(30)$ & \\
\hline $\mathrm{G}$ & $0.39712(18)$ & $0.91894(06)$ & $1.19145(20)$ & & 1.58857 (19) & \\
\hline $\mathrm{H}$ & $0.62002(11)$ & $0.59769(22)$ & $1.33297(09)$ & & $1.95299(10)$ & \\
\hline I & 0.09730 & 0.96427 & 1.03070 & & $1.12800(42)$ & \\
\hline $\mathrm{J}$ & 1.0508 & & 1.606 & & 2.65 & \\
\hline $\mathrm{K}$ & 0.580 & & 1.294 & & & \\
\hline $\mathrm{L}$ & 0.112 & & 1.005 & & & \\
\hline $\mathrm{M}$ & 0.38 & & 1.25 & & & \\
\hline $\mathrm{N}$ & 0.24 & & 1.1 & & & \\
\hline $\mathrm{O}$ & 0.70 & & 1. & & 2.2 & \\
\hline $\mathrm{P}$ & 0.46 & & & & & \\
\hline $\mathrm{Q}$ & 0.43 & & 1. & & & \\
\hline $\mathrm{R}$ & 0.07 & & & & & \\
\hline $\mathrm{S}$ & 0.0 & & & & & \\
\hline $\mathrm{T}$ & 0.25 & & 1.100 & & 1.35 & \\
\hline $\mathrm{U}$ & 1.005 & & 1.468 & & 2.47 & \\
\hline $\mathrm{V}$ & 0.11 & & ) & & 1.14 & \\
\hline $\mathrm{W}$ & 0.20 & & ) & & 1.31 & \\
\hline $\mathrm{X}$ & $0.34 \mathrm{C}$ & & ) & & 1.57 & \\
\hline $\mathrm{Y}$ & 0.229 & & ) & & 1.33 & \\
\hline Z & 1.13 & & 7 & & 2.75 & \\
\hline $\mathrm{AA}$ & 0.61 & & ) & & 1.92 & \\
\hline $\mathrm{AB}$ & 0.384 & & 1.158 & & 1.54 & \\
\hline $\mathrm{AC}$ & 0.085 & 7) & 1.033 & & 1.11 & 56) \\
\hline $\mathrm{AD}$ & 0.089 & 9) & 1.031 & & 1.12 & $6(49)$ \\
\hline$\overline{\mathrm{AE}}$ & $0.67389(09)$ & 16) & 1.304 & & 1.978 & $(21)$ \\
\hline $\mathrm{AF}$ & $0.18967(36)$ & $0.87316(09)$ & 1.084 & $1.50689(07)$ & $1.27449(36)$ & $2.38005(07)$ \\
\hline $\mathrm{AG}$ & $0.34264(24)$ & $0.05786(53)$ & $1.06549(35)$ & $1.01392(54)$ & $1.40814(24)$ & $1.07178(54)$ \\
\hline $\mathrm{AH}$ & $0.13690(38)$ & $0.38862(28)$ & $1.05307(38)$ & $5(36)$ & $1.18998(38)$ & $1.54577(31)$ \\
\hline AI & $0.07119(51)$ & 0.22279 (44) & $1.01845(49)$ & 1.10909 (42) & $1.08964(51)$ & $1.33189(43)$ \\
\hline AJ & $0.42780(17)$ & $0.25383(41)$ & $1.22181(18)$ & $1.15865(35)$ & $1.64961(17)$ & $1.41248(38)$ \\
\hline $\mathrm{AK}$ & $0.22043(33)$ & $0.28245(35)$ & $1.08894(32)$ & $1.19233(29)$ & $1.30937(33)$ & $1.47478(34)$ \\
\hline $\mathrm{AL}$ & $1.21440(02)$ & $0.72479(17)$ & $1.60267(05)$ & 1.37347 (13) & $2.81707(02)$ & $2.09827(16)$ \\
\hline AM & $0.17441(37)$ & $5(33)$ & $1.08463(34)$ & $1.17166(33)$ & $1.25904(37)$ & $1.50730(33)$ \\
\hline $\mathrm{AN}$ & $0.38418(20)$ & $7(04)$ & $1.14317(23)$ & $1.60159(04)$ & $1.52735(23)$ & $2.57746(04)$ \\
\hline $\mathrm{AO}$ & $2.58951(01)$ & $0.37248(30)$ & $2.57317(01)$ & $1.25001(23)$ & $5.16268(01)$ & $1.62249(25)$ \\
\hline $\mathrm{AP}$ & $1.01168(05)$ & $0.87536(08)$ & $1.55880(06)$ & $1.55029(05)$ & $2.57047(06)$ & $2.42566(05)$ \\
\hline$\overline{\mathrm{AQ}}$ & $0.24478(27)$ & $0.87769(07)$ & $1.09177(31)$ & $1.30295(19)$ & $1.33655(28)$ & $2.18064(11)$ \\
\hline$\overline{\mathrm{AR}}$ & 0.071 & & 1.00553 & & $1.07738(55)$ & 1.08710 \\
\hline AS & $0.22353(31)$ & $0.86599(10)$ & $1.09713(30)$ & $1.41556(11)$ & $1.32065(31)$ & $2.28155(09)$ \\
\hline
\end{tabular}




\begin{tabular}{|c|c|c|c|c|c|c|}
\hline [1] & $\begin{array}{c}\text { ODFL } \\
=\text { t.I-DFOM } \\
{[2]} \\
\end{array}$ & $\begin{aligned} &(\text { adj)ODFL } \\
&=(\mathbf{a d j}) \text { t.I-DFOI } \\
& {[3] }\end{aligned}$ & $\begin{array}{r}\text { OIrFL } \\
=\text { t.I-IrFO } \\
{[4]}\end{array}$ & $\begin{array}{c}\text { (adj)OIrFL } \\
=(\text { adj)t.I-IrFOM } \\
{[5]}\end{array}$ & $\begin{aligned} & \text { OTFL } \\
&= \text { t.I-FOM } \\
& {[6] } \\
&\end{aligned}$ & $\begin{aligned} &(\mathbf{a d j}) \text { OTFL } \\
&=(\mathbf{a d j}) \mathbf{t} . \mathrm{I}-F O M \\
& {[7] }\end{aligned}$ \\
\hline $\mathrm{AT}$ & $0.23558(29)$ & $0.74786(13)$ & $1.05756(37)$ & $1.20984(25)$ & $1.29314(34)$ & $1.95770(22)$ \\
\hline $\mathrm{AU}$ & 0.22 & 0 . & 1.0582 & 1. & 1.28 & 19) \\
\hline $\mathrm{AV}$ & 0.0 & 0 & 1.021 & 1. & 1.08 & 1) \\
\hline $\mathrm{AW}$ & 0.117 & 0.1 & 1.018 & 18) & 1.135 & 46) \\
\hline $\mathrm{AX}$ & 0.630 & & 1.2060 & 1.30 & 1.836 & 2.158 \\
\hline AY & 0.000 & 0.00 & 1.0000 & 1.00 & 1.000 & 59) \\
\hline $\mathrm{AZ}$ & $0.10194(43)$ & 0.03 & $1.01888(47)$ & 1.01 & $1.12083(45)$ & $1.04625(57)$ \\
\hline BA & $0.03328(56)$ & 0.03 & $1.00459(57)$ & (58) & $1.03787(56)$ & $1.03407(58)$ \\
\hline $\mathrm{BB}$ & $0.00776(58)$ & $0.08731(50)$ & $1.00574(55)$ & 1.072 & $1.01351(58)$ & $1.15974(50)$ \\
\hline $\mathrm{BC}$ & $0.25562(25)$ & $0.26286(38)$ & $1.10609(27)$ & $1.15086(37)$ & $1.36172(26)$ & $1.41373(37)$ \\
\hline $\mathrm{BD}$ & $0.10342(42)$ & $0.26824(37)$ & $1.01400(52)$ & $1.06532(44)$ & $1.11742(47)$ & $1.33356(42)$ \\
\hline $\mathrm{BE}$ & $0.07045(52)$ & $0.05136(54)$ & $1.03239(41)$ & $1.03341(49)$ & $1.10284(48)$ & $1.08477(53)$ \\
\hline $\mathrm{BF}$ & $0.09685(45)$ & $0.69102(19)$ & $1.04419(39)$ & $1.34421(16)$ & $1.14104(40)$ & $2.03523(18)$ \\
\hline BG & $0.01162(57)$ & $0.04742(55)$ & $1.00271(58)$ & $1.00907(56)$ & $1.01432(57)$ & $1.05649(55)$ \\
\hline
\end{tabular}

Note: The results have been obtained by author's calculations. The primary data were originated from the Hellenic Statistical Authority $(2017,2019)$. Numbers in parenthesis represent sectoral rankings. The sectoral terminology of Hellenic Statistical Authority (with which the primary data have been published in Eurostat) was followed.

Due to the fact that the output constitutes an exception from all the others kind "S" of effects as for its causality (equations 24, 25, 26, 27), another one paradigm has been chosen for the description of deviations among the measurements and the classifications of adjusted and non-adjusted indicators. For this scope has been estimated the dispersed multiplicative effects of generated income. The analysis for the adjusted and the non-adjusted forward linkages indices of income into the Table no. 4 facilitates the readers to comprehend easier the architectural differences that exist at the configuration of various per kind " $\mathrm{S}$ " indices, against to the output case (equations 28, 29, 30, 31).

As it is clear, the relevant adjusted and the non-adjusted direct, indirect, truncated and total linkages indices of income [WDFL, (adj)WDFL, WIrFL, (adj)WIrFL, TrWTFL , (adj)TrWTFL, WTFL, (adj)WTFL] are differentiated each other as regards their magnitudes and their rankings (Table no. 4). Due to the fact that in any case the adjusted type I forward multipliers [ $($ adj $) t . I-D F I M,($ adj $) t . I-I r F I M,(a d j) t . I-F I M]$ can be considered as more credible indicators than the linkages indices, in the Table no. 4 are included their results for the detection of noteworthy sectors of Greek productive network as regards the sectoral potentials for frontloading multiplicative impacts on the economy's income. Looking at the column [13] of adjusted total type I forward income multipliers $[(a d j) t . I-F I M]$ is deduced that these sectors are: the real estate services (AO: 5.89914, $1 \mathrm{st})$, the coke and refined petroleum products ( $\mathrm{J}: 5.53950,2 \mathrm{nd})$, the mining and quarrying products (D: 4.66284, 3rd), the rubber and plastic products (M: 3.87831, 4th), the paper products (H: $3.37916,5$ th), the repair services of computers and personal and households' goods (BF: $3.30490,6$ th), the wood products $(\mathrm{G}: 3.25231,7$ th), the chemical products $(\mathrm{K}$ : $3.12510,8$ th $)$, the basic metals $(\mathrm{O}: 3.01490,9$ th $)$, and the rental and leasing services (AU: $2.84688,10$ th). 


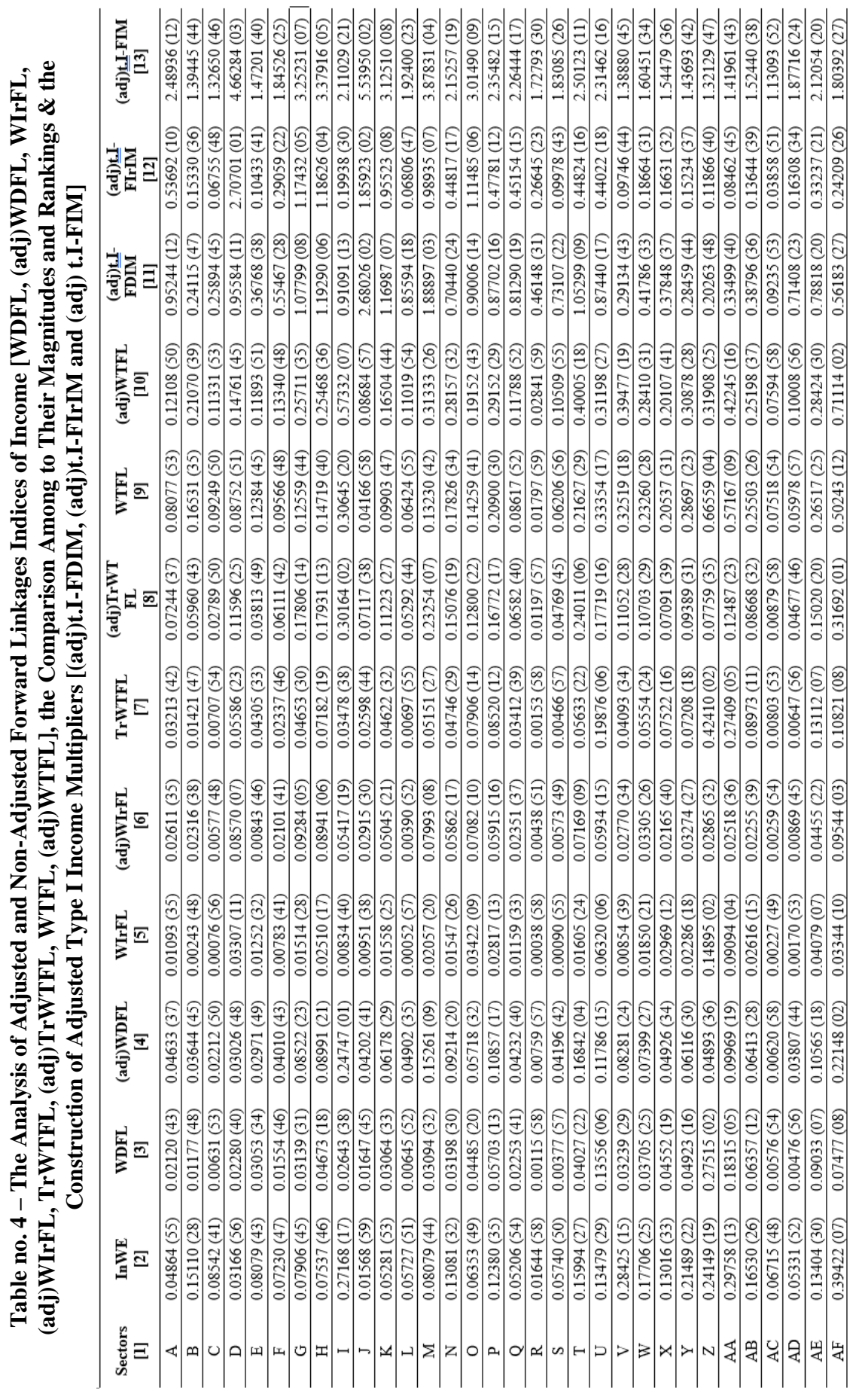




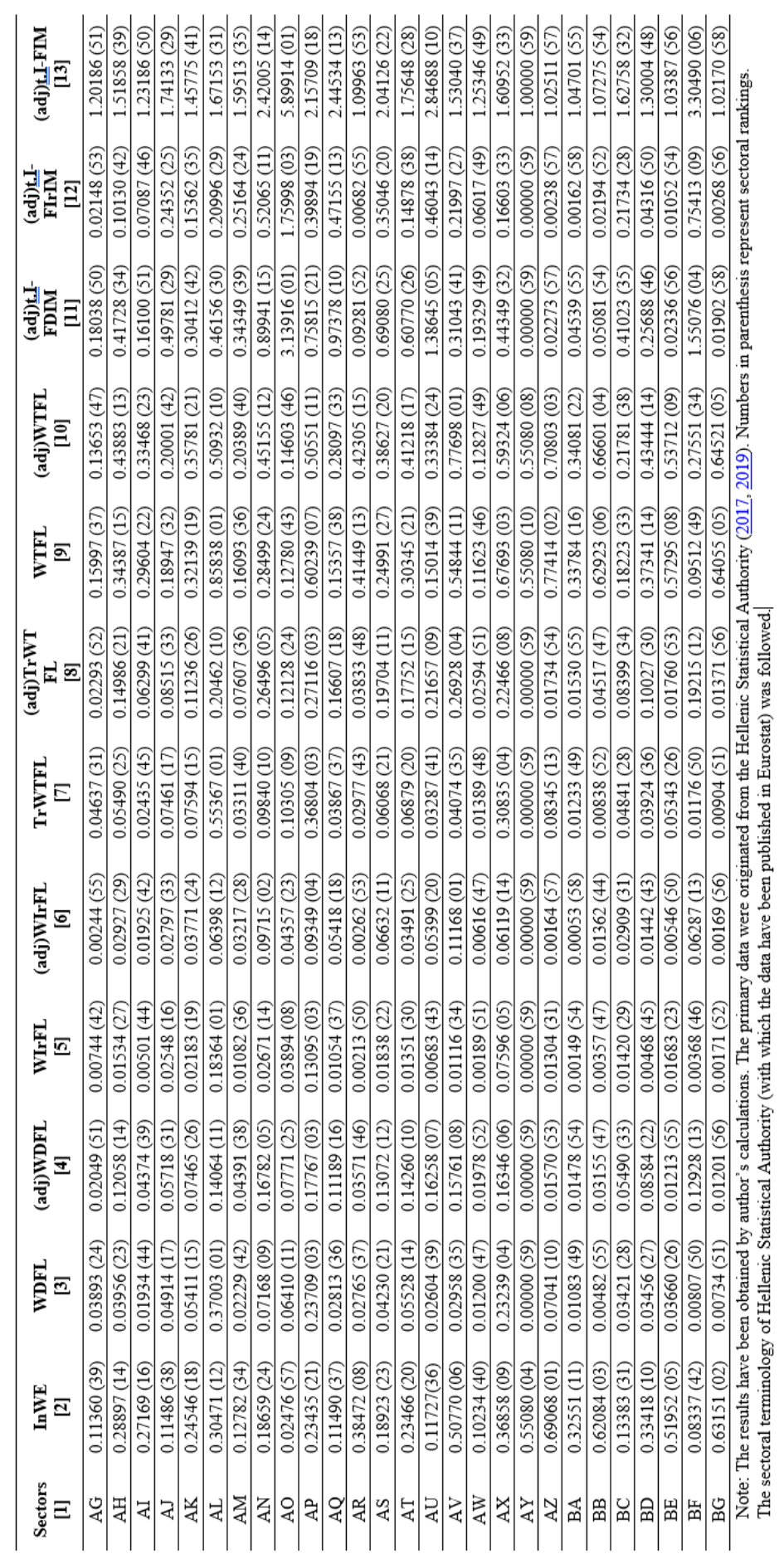




\section{CONCLUSIONS}

The policy planners systematically ignore the sectoral forward impacts in the productive network. Especially, at these exceptions of literature in which the estimation of sectoral forward multiplicative effects to the whole of economy, per factor "S", is attempted through the conventional quantitative backward-to-forward approach, is observed that deceitful measurements and classifications are generated. In contradistinction to the traditional consideration, another one, the quantitative adjusted forward-to-backward analysis seems to be the appropriate solution for the calculation of forward spillovers. The generated magnitudes and the rankings from the application of adjusted quantitative forward-tobackward approach differ substantially against to them of conventional backward-to-forward consideration. The outcomes of adjusted type I forward multipliers per factor "S" end up to be the necessary tools for the completion of developmental patterns, adding the right way for the forward dimension in the process for the determination of propulsive sectors.

\section{ORCID}

Argyrios D. Kolokontes (D) http://orcid.org/0000-0003-4161-0596

\section{References}

Adamou, K. N., 2007. Linkages, Impact and Feedback in Light of Linear Similarity. Paper presented at the 16th International Input-Output Conference, International Input-Output Association. https://www.iioa.org/conferences/16th/papers.html.

Almon, C., 1966. The American Economy to 1975. An Inderindustry Forecast: Harper and Row Publisher.

Aroche Reyes, F., and Marquez Mendoza, A. M., 2015. The Demand Driven and the Supply-Sided Input-Output Models. Notes for the Debate. MPRA, 61132. https://mpra.ub.unimuenchen.de/61132/.

Augusztinovics, M., 1970. Methods of International and Intertemporal Comparison of Structure. In P. A. Carter and A. Brody (Eds.), Contributions to Input-Output Analysis. Proceedings of the Fourth International Conference on Input-Output Techniques (pp. 248-269). Amsterdam: North Holland Publishing Company.

Ball, J. R., 1981. On Lawrence R. Klein's Contributions to Economics. The Scandinavian Journal of Economics, 83(1), 81-103. http://dx.doi.org/10.2307/3439807

Baranov, A., Pavlov, V., and Suslov, V., 2014. The System of Dynamic Input-Output Models for Forecasting the Development of Russian Economy at the National and Regional Levels. In A. Baranov and V. Suslov (Eds.), Development of Macro and Industrial Methods of Economic Analysis. Proceedings of the 21st INFORUM World Conference (pp. 34-51). Novosibirsk: Institute of Economics and Industrial Engineering of Siberian Branch of Russian Academy of Sciences.

Baumol, J. W., and Wolff, N. E., 1994. A Key-Role of Input-Output Analysis in Policy Design. Regional Science and Urban Economics, 24(1), 93-113. http://dx.doi.org/10.1016/0166-0462(94)90021-3

Bayers, B. W., 1976. Empirical Identification of Key Sectors: Some Further Evidence. Environment \& Planning A, 8(2), 231-236. http://dx.doi.org/10.1068/a080231

Bekhet, A. H., 2010. Ranking Sectors Changes of the Malaysian Economy: Input-Output Approach. International Business Research, 3(1), 107-130. http://dx.doi.org/10.5539/ibr.v3n1p107 
Bekhet, A. H., 2011. Output, Income and Employment Multipliers in Malaysian Economy: Input-Output Approach. International Business Research, 4(1), 208-223. http://dx.doi.org/10.5539/ibr.v4n1p208

Bekhet, A. H., 2012. Assessing Development Efficiency in Malaysian Economy: Input-Output Approach. International Journal of Economics and Business Research, 4(3), 297-325. http://dx.doi.org/10.1504/IJEBR.2012.046823

Bekhet, A. H., and Yasmin, T., 2017. Investigating Source Change of Economic Development in Malaysia: Total Input Cost Approach. International Journal of Economics and Business Research, 14(2), 214-236. http://dx.doi.org/10.1504/IJEBR.2017.086707

Bekhet, H. A., Abdullah, T. A. R. b. T., and Yasmin, T., 2016. Measuring Output Multipliers of Energy Consumption and Manufacturing Sectors in Malaysia during the Global Financial Crisis. Procedia Economics and Finance, 35, 179-188. http://dx.doi.org/https://doi.org/10.1016/S22125671(16)00023-X

Belegri-Roboli, A., Demertzi, A., Markaki, M., and Michailides, P., 2011a. An Input-Output Analysis of Environmental Effects of Infrastructure Investments in the Greek Economy: The Case of 'Attiki Odos' Motorway. Conference Papers: ersa10p48.

Belegri-Roboli, A., Demertzi, A., Markaki, M., and Michailides, P., 2016. The Macroeconomic Impacts of the Attiki Odos Motorway in the Greek Economy: An Input-Output Analysis. MPRA, 74429. https://mpra.ub.uni-muenchen.de/74429/.

Belegri-Roboli, A., and Markaki, M., 2010. Employment Determinants in an Input-Output Framework: Structural Decomposition Analysis and Production Technology. Bulletin of Political Economy, 4(2), 145-156.

Belegri-Roboli, A., Markaki, M., and Michailides, P., 2011b. Labour Productivity Changes and Working Time: The Case of Greece. Economic Systems Research, 23(3), 329-339. http://dx.doi.org/10.1080/09535314.2011.595777

Bon, R., 1986. Comparative Stability Analysis of Demand-Side and Supply-Side Input-Output Models. International Journal of Forecasting, 2(2), 231-235. http://dx.doi.org/10.1016/01692070(86)90112-3

Bon, R., and Bing, X., 1993. Comparative Stability Analysis of Demand-Side and Supply-Side InputOutput Models in the U.K. Applied Economics, 25(1), 75-79. http://dx.doi.org/10.1080/00036849300000116

Bon, R., and Yashiro, T., 1996. Comparative Stability Analysis of Demand-Side and Supply-Side InputOutput Models: The Case of Japan 1960-90. Applied Economics Letters, 3(5), 349-354. http://dx.doi.org/10.1080/135048596356492

Bonfiglio, A., 2005. A Sensitivity Analysis of the Impact of CAP Reform. Alternative Methods of Constructing Regional I-O Tables. (PhD), Polytechnic University of Marche, Department of Economics, Ancona.

Briassoulis, H., 1991. Methodological Issues: Tourism Input-Output Analysis. Annals of Tourism Research, 18(3), 485-495. http://dx.doi.org/10.1016/0160-7383(91)90054-F

Cai, J., and Leung, P., 2004. Linkage Measures: A Revisit and a Suggested Alternative. Economic Systems Research, 16(1), 65-85. http://dx.doi.org/10.1080/0953531032000164800

Carroll, M. T., 1980. Tests of the RAS and Modified RAS Updating Techniques on a Regional InputOutput Model. (PhD), Oregon State University, Oregon, U.S.A.

Cella, G., 1984. The Input - Output Measurement of Interindustry Linkages. Oxford Bulletin of Economics and Statistics, 46(1), 73-84. http://dx.doi.org/10.1111/j.14680084.1984.mp46001005.x

Chen, K., 1976. On the Choice and Linkage of Large Scale Forecasting Models. Technological Forecasting and Social Change, 9(1-2), 27-33. http://dx.doi.org/10.1016/0040-1625(76)90042-1

Choi, S. G., Ji, H., and Zhao, X., 2014, 26-19 August 2014. Identifying Key-Sectors Using Regional Input-Output Model at Sub-National Level: The Case of Korean Economy. Paper presented at the 
54th Congress of the European Regional Science Association: Regional Development and Globalization: Best Practices, St. Petersburg, Russia, European Regional Science Association.

Chuenchum, P., Pattanapong, N., Suttinon, P., and Ruangrassamee, P., 2018. Cross-Sectoral Analysis of Water Usage in Thailand Using Input-Output Model. Engineering Journal (New York), 22(6), 93-115. http://dx.doi.org/10.4186/ej.2018.22.6.93

Ciobanu, C., Mattas, K., and Psaltopoulos, D., 2004. Structural Changes in Less Developed Areas: An Input- Output Framework. Regional Studies, 38(6), 603-614. http://dx.doi.org/10.1080/003434042000240914

Clements, J. B., 1990. On the Decomposition and Normalization of Interindustry Linkages. Economics Letters, 33(4), 337-340. http://dx.doi.org/10.1016/0165-1765(90)90084-E

Clements, J. B., and Rossi, W. J., 1991. Interindustry Linkages and Economic Development: The Case of Brazil Reconsidered. The Developing Economies, 29(2), 166-187. http://dx.doi.org/10.1111/j.1746-1049.1991.tb00205.x

Cronin, J. F., 1984. Analytical Assumptions and Causal Ordering in Interindustry Modeling. Southern Economic Journal, 51(2), 521-529. http://dx.doi.org/10.2307/1057829

Cuello, A. F., Mansouri, F., and Hewings, D. J. G., 1992. The Identification of Structure at a Sectoral Level: A Reformulation of Hirschman-Rasmussen Key-Sector Indices. Economic Systems Research, 4(4), 285-296. http://dx.doi.org/10.1080/09535319200000027

de Lima Almeida, M. L., and de Freitas Balanco, A. P., 2020. Application of Multivariate Analysis as Complementary Instrument in Studies About Structural Changes: An Example of the Multipliers in the US Economy. Structural Change and Economic Dynamics, 53, 189-207. http://dx.doi.org/10.1016/j.strueco.2020.02.006

de Mesnard, L., 1990. Biproportional Method for Analyzing Interindustry Dynamics: The Case of $\begin{array}{llll}\text { France. Economic } & \text { Systems 271-293. }\end{array}$ http://dx.doi.org/10.1080/09535319000000019

de Mesnard, L., 1995. The Variations of Technical and Allocation Coefficients: Are they Comparable Really? . HAL Working Papers, hal-01545726.

de Mesnard, L., 1997. A Biproportional Filter to Compare Technical and Allocation Coefficient Variations. Journal of Regional Science, 37(4), 541-564. http://dx.doi.org/10.1111/0022 4146.00069

de Mesnard, L., 1999. Analyzing Structural Change: Two New Biproportional Tools. Application to the Input-Output Table of France (1980-1996). European Regional Science Association (ERSA) Conference Paper, ersa99pa203. http://www-sre.wu.ac.at/ersa/ersaconfs/ersa99/Papers/a203.pdf.

de Mesnard, L., 2000a. About the Criteria of Output Coincidence for Forecasts to Determine the Orientation of the Economy. Application for France, 1980-1997. HAL Working Papers, 01526521. https://hal.archives-ouvertes.fr/hal-01526521/document.

de Mesnard, L., 2000b. Bicausative Matrices to Measure Structural Change: Are They a Good Tool? The Annals of Regional Science, 34(3), 421-449. http://dx.doi.org/10.1007/s001680000023

de Mesnard, L., 2002a. Consistency of the Supply-Driven Model: A Typological Approach. Paper presented at the 14th International Conference on Input-Output Techniques, Montreal.

de Mesnard, L., 2002b. Forecast Output Coincidence and Biproportion: Two Criteria to Determine the Orientation of an Economy. Comparison for France (1980-1997). Applied Economics, 34(16), 2085-2091. http://dx.doi.org/10.1080/00036840210128771

de Mesnard, L., 2004. Understanding the Shortcomings of Commodity-Based Technology in InputOutput Models: An Economic Circuit Approach. Journal of Regional Science, 44(1), 125-141. http://dx.doi.org/10.1111/j.1085-9489.2004.00330.x

de Mesnard, L., 2009. Is the Ghosh Model Interesting? Journal of Regional Science, 49(2), 361-372. http://dx.doi.org/10.1111/j.1467-9787.2008.00593.x

de Mesnard, L., 2013. Is the Leontief Input-Output Model a Production-Prices Model? . Paper presented at the The Pioneers of Linear Models of Production, Paris: University Paris Quest. 
de Mesnard, L., 2016. Price consistency in the Leontief model. [Price consistency in the Leontief model]. Papers in Political Economy, 71(2), 181-201. http://dx.doi.org/10.3917/cep.071.0181

de Mesnard, L., 2019a. Returning to the Question of Prices in Input-Output Models (Preliminary Version).

de Mesnard, L., 2019b. Why the Leontief's Price Model is Superfluous. https://www.researchgate.net/publication/337464969_Input_output_Analysis_Why_the_price_m odels_are_superfluous.

Deman, S., 1988. Stability of Supply Coefficients and Consistency of Supply-Driven and DemandDriven Input-Output Models. Environment and Planning A. Economy and Space, 20(6), 811-816. http://dx.doi.org/10.1068/a200811

Deman, S., 1991. Stability of Supply Coefficients and Consistency of Supply-Driven and DemandDriven Input-Output Models: A Reply. Environment and Planning A: Economy and Space, 23(12), 1811-1817. http://dx.doi.org/10.1068/a231811

Dietzenbacher, E., 1997. In Vindication of the Ghosh Model: A Reinterpretation as a Price Model. Journal of Regional Science, 37(4), 629-651. http://dx.doi.org/10.1111/0022-4146.00073

Dietzenbacher, E., 2001. An Intercountry Decomposition of Output Growth in EC Countries In M. L. Lahr and E. Dietzenbacher (Eds.), Input-Output Analysis: Frontiers and Extensions (pp. 121-142). Hampshire: Palgrave Macmillan.

Dietzenbacher, E., 2002. Interregional Multipliers: Looking Backward, Looking Forward. Regional Studies, 36(2), 125-136. http://dx.doi.org/10.1080/00343400220121918

Dietzenbacher, E., 2005. More on Multipliers. Journal of Regional Science, 45(2), 421-426. http://dx.doi.org/10.1111/j.0022-4146.2005.00377.x

Dietzenbacher, E., and Van Der Linden, A. J., 1997. Sectoral and Spatial Linkages in the EC Production Structure. Journal of Regional Science, 37(2), 235-257. http://dx.doi.org/10.1111/00224146.00053

Economakis, G., Markaki, M., and Anastasiadis, A., 2015. Structural Analysis of the Greek Economy. The Review of Radical Political Economics, 47(3), 224-245. http://dx.doi.org/10.1177/0486613414542779

Eiser, D., and Roberts, D., 2002. The Employment and Output Effect of Changing Patterns of Afforestation in Scotland. Journal of Agricultural Economics, 53(1), 65-81. http://dx.doi.org/10.1111/j.1477-9552.2002.tb00006.x

Escaith, H., 2014. Exploring the Policy Dimensions of Trade in Value-Added. MPRA, 5989. https://mpra.ub.uni-muenchen.de/59891/.

Ferreira, V., Pié, L., and Terceño, A., 2020. The Role of the Foreign Sector in the Spanish Bioeconomy: Two Approaches Based on SAM Linear Models. International Journal of Environmental Research and Public Health, 17(24), 9381. http://dx.doi.org/10.3390/ijerph17249381

Freytag, A., and Fricke, S., 2017. Sectoral Linkages of Financial Services as Channels of Economic Development - An Input-Output Analysis of the Nigerian and Kenyan Economies. Review of Development Finance, 7(1), 36-44. http://dx.doi.org/10.1016/j.rdf.2017.01.004

Ghosh, A., 1958. Input-Output Approach in an Allocation System. Economica, 25, 58-64. http://dx.doi.org/10.2307/2550694

Giannakis, E., and Mamuneas, P. T., 2018. Sectoral Linkages and Economic Crisis: An Input-Output Analysis of the Cypriot Economy. Cyprus Economic Policy Review, 12(1), 28-40.

Giarratani, F., 1976. Application of an Interindustry Supply Model to Energy Issues. Environment and Planning A: Economy and Space, 8(4), 447-454. http://dx.doi.org/10.1068/a080447

Giarratani, F., 1980. The Scientific Basis for Explanation in Regional Analysis. Papers in Regional Science, 45(1), 185-196. http://dx.doi.org/10.1111/j.1435-5597.1980.tb01107.x

Grassini, M., 2014. A Lot of Algebra and a Little Economics. Linkages in Input-Output Modeling. 21st INFORUM World Conference. Development of Macro and Industrial Methods of Economic Analysis. Institute of Economics and Industrial Engineering of Siberian Branch of Russian Academy of Sciences. Listvyanka. 
Gruver, W. G., 1989. On the Plausibility of Supply-Driven Input-Output Model: A Theoretical Basis for Input Coefficient Change. Journal of Regional Science, 29(3), 441-450. http://dx.doi.org/10.1111/j.1467-9787.1989.tb01389.x

Guang, F., and Wen, L., 2020. Growth pattern changes in China's energy consumption. Environmental Science and Pollution Research International, 27(22), 28360-28373. http://dx.doi.org/10.1007/s11356-020-09206-0

Guerra, A.-I., and Sancho, F., 2010. A Comparison of Input-Output Models: Ghosh Reduces to Leontief (But "Closing" Ghosh Makes It More Plausible). Barcelona Economic Working Paper Series, 450.

Guo, D., and Hewings, D. J. G., 2001. Comparative Analysis of China's Economic Structures Between 1987 and 1997: An Input-Output Prospective. Regional Economic Applications Laboratory (REAL) Discussion Papers, 01-T-04 2001.

Han, C., Többen, J., Kuckshinrichs, W., Schröder, M., and Witthaut, D., 2020, 2020//. Reconstruction of Demand Shocks in Input-Output Networks. Paper presented at the Complex Networks XI, Cham.

Hastuti, S. H., Hartono, D., Putranti, T. M., and Imansyah, M. H., 2021. The drivers of energy-related $\mathrm{CO} 2$ emission changes in Indonesia: Structural decomposition analysis. Environmental Science and Pollution Research International, 28, 9965-9978. http://dx.doi.org/10.1007/s11356-02011414-7

Hellenic Statistical Authority, 2017. Sectoral Employment 2015. from http://www.statistics.gr/el/statistics/-/publication/SEL54/2015

Hellenic Statistical Authority, 2019. The Symmetric Input-Output Table of Greece, 2015. from http://www.statistics.gr/el/statistics/-/publication/SEL38/2015

Hirschman, O. A., 1958. The Strategy of Economic Development. Yale: Yale University Press.

Hristu-Varsakelis, D., Karagianni, S., Pempetzoglou, M., and Sfetsos, A., 2012. Optimizing Production in the Greek Economy: Exploring the Interaction Between Greenhouse Gas Emissions and Solid Waste via Input-Output Analysis. Economic Systems Research, 24(1), 57-75. http://dx.doi.org/10.1080/09535314.2011.572065

Humavindu, N. M., and Stage, J., 2013. Key Sectors of the Namibian Economy. Journal of Economic Structures, 2, 1-15. http://dx.doi.org/10.1186/2193-2409-2-1

Hung, M. D., Thai, Q. N., and Trinh, B., 2020. Income Multipliers in Input-Output Analysis: Case of Vietnam. European Journal of Business and Management Research, 5(2). http://dx.doi.org/10.24018/ejbmr.2020.5.2.285

Imansyah, H. M., Putranti, T., and Mangkurat, L., 2017. The Identification of Key Sector in CO2 Emissions in Production Perspective of Indonesia: An Input-Output Analysis. Sustainable Future for Human Security, 5(2), 21-29. http://dx.doi.org/10.24910/jsustain/5.2/2129

Jackson, W. R., Rogerson, P., Plane, D., and Huallachain, O., 1990. A Causative Matrix Approach to Interpreting Structural Change. Economic Systems Research, 2(3), 259-269. http://dx.doi.org/10.1080/09535319000000018

Jahn, M., 2015. A Location-Quotient Based Interregional Input-Output (IRIOLQ) Framework (Preliminary Version). Hamburg Institute of International Economics, HWWI Research, 161.

Jensen, C. R., 1976. An Inderindustry Study of the Central Queensland Economy. (PhD), University of Queensland, Queensland, Australia.

Jensen, C. R., Mandeville, D. T., and Karunaratne, D. N., 1979. Regional Economic Planning: Generation of Regional Input-Output Analysis: Croom Helm Ltd.

Jones, P. L., 1976. The Measurement of Hirschmanian Linkages. The Quarterly Journal of Economics, 90(2), 323-333. http://dx.doi.org/10.2307/1884635

Kakderi, C., and Tasapoulou, A., 2017. Regional Economic Resilience: The role of National and Regional Policies. European Planning Studies, 25(8), 1435-1453. http://dx.doi.org/10.1080/09654313.2017.1322041 
Kelly, S., 2015. Estimating Economic Loss from Cascading Infrastructure Failure: A Perspective on Modelling Interdependency. Infrastructure Complexity, 2(1), 7. http://dx.doi.org/10.1186/s40551015-0010-y

Kelly, S., Tyler, P., and Crawford-Brown, D., 2016. Exploring Vulnerability and Interdependency of UK Infrastructure Using Key-Linkages Analysis. Networks and Spatial Economics, 16(3), 865892. http://dx.doi.org/10.1007/s11067-015-9302-x

Klein, R. L., and Glickman, J. N., 1977. Econometric Model Building at Regional Level. Regional Science and Urban Economics, 7(1-2), 3-23. http://dx.doi.org/10.1016/0166-0462(77)90016-3

Kolokontes, D. A., and Chatzitheodoridis, F., 2008. Unemployment and Development Priorities and Prospects of Western Macedonia Region Greece: A Sectoral Approach. The Empirical Economics Letters, 7(11), 1103-1115.

Kolokontes, D. A., Karafyllis, C., and Chatzitheodoridis, F., 2008. Peculiarities and Usefulness of Multipliers, Elasticities and Location Quotients for the Regional Development Planning: Another View. Romanian Journal of Regional Science, 2(2), 118-133.

Kolokontes, D. A., Kontogeorgos, A., Loizou, E., and Chatzitheodoridis, F., 2018. Key-Sectors Attractiveness of the Greek Economy: An Input-Output Approach. Applied Econometrics and International Development, 18, 35-54.

Kolokontes, D. A., Kontogeorgos, A., Loizou, E., and Chatzitheodoridis, F., 2019. Input-Output Models and Derived Indicators: A Critical Review. Scientific Annals of Economics and Business, 66(3), 267-308. http://dx.doi.org/10.47743/saeb-2019-0026

Kolokontes, D. A., Kontogeorgos, A., Loizou, E., and Chatzitheodoridis, F., 2020. Decomposition Analysis for the Comparison and the Comprehension of Conventional Input-Output Impacts' Indicators: An Empirical Paradigm. Scientific Annals of Economics and Business, 67(2), 197-217. http://dx.doi.org/10.47743/saeb-2020-0011

Kuroda, M., and Nomura, K., 2004. Technological change and accumulated capital: a dynamic decomposition of Japan's growth. In E. Dietzenbacher and M. L. Lahr (Eds.), Wassily Leontief and Input-Output Economics (pp. 256-293). Cambridge: Cambridge University Press. http://dx.doi.org/ 10.1017/CBO9780511493522.016

Lahr, L. M., 1993. A Review of the Literature Supporting the Hybrid Approach to Constructing Regional Input-Output Models. Economic Systems Research, 5(3), 277-293. http://dx.doi.org/10.1080/09535319300000023

Leontief, W. W., 1936a. Composite Commodities and the Problem of Index Numbers. Econometrica, 4(1), 39-59. http://dx.doi.org/10.2307/1907120

Leontief, W. W., 1936b. Quantitative Input and Output Relations in the Economic System of the United States. The Review of Economics and Statistics, 18(3), 105-125. http://dx.doi.org/10.2307/1927837

Leontief, W. W., 1937. Interrelation of Prices, Output, Savings and Investment. The Review of Economics and Statistics, 19(3), 109-132. http://dx.doi.org/10.2307/1927343

Leontief, W. W., 1941. The Structure of American Economy, 1919-1929: An Empirical Application of Equilibrium Analysis. The Canadian Journal of Economics and Political Science / Revue canadienne d'Economique et de Science politique, 8(1), 124-126. http://dx.doi.org/10.2307/137008

Leontief, W. W., 1944. Output, Employment, Consumption and Investment. The Quarterly Journal of Economics, 58(2), 290-314. http://dx.doi.org/10.2307/1883321

Leontief, W. W., 1947. Introduction to a Theory of the Internal Structure of Functional Relationships. Econometrica, 15(4), 361-373. http://dx.doi.org/10.2307/1905335

Leontief, W. W., 1951. Input-Output Economics. Scientific American, 185(4), 15-21.

Leontief, W. W., 1953. Domestic Production and Foreign Trade; The American Capital Position ReExamined. Proceedings of the American Philosophical Society, 97(4), 332-349.

Leontief, W. W., 1961. Lags and Stability of Dynamic Systems. Econometrica, 29(4), 659-669. http://dx.doi.org/10.2307/1911811 
Leontief, W. W., 1971. Theoretical Assumptions and Non Observed Facts. The American Economic Review, 61(1), 1-7.

Leontief, W. W., 1974. Structure of the World Economy. In D. H. Kurz, E. Dietzenbacher and C. Lager (Eds.), Input - Output Analysis, Volume II. Chetlenham UK / Northampton, MA, USA: Elgar Reference Collection.

Leontief, W. W., 1986. Input-Output Economics (2nd ed.). Oxford: Oxford University Press.

Leontief, W. W., 1991. The economy as a circular flow. Structural Change and Economic Dynamics, 2(1), 181-212. http://dx.doi.org/10.1016/0954-349X(91)90012-H

Leontief, W. W., and Strout, A., 1963. Multiregional Input-Output Analysis. In T. Barna (Ed.), Structural Interdependence and Economic Development: Proceedings of an International Conference on Input-Output Techniques, Geneva, September 1961 (pp. 119-150). London: Palgrave Macmillan UK. http://dx.doi.org/10.1007/978-1-349-81634-7_8

Lian, C., and Haimes, Y. Y., 2006. Managing the Risk of Terrorism to Interdepended Infrastructure Systems Through the Dynamic Inoperability Input-Output Model. Systems Engineering, 9(3), 241258. http://dx.doi.org/10.1002/sys.20051

Loizou, E., Chatzitheodoridis, F., Michailidis, A., Tsakiri, M., and Theodossiou, G., 2015. Linkages of the Energy Sector in Greek Economy: An Input-Output Approach. International Journal of Energy Sector Management, 9(3), 393-411. http://dx.doi.org/10.1108/IJESM-06-2013-0004

Mariolis, T., Ntemiroglou, N., and Soklis, G., 2018. The Static Demand Multipliers in a Joint Production Framework. Comparative Findings for the Greek, Spanish and Eurozone Economies. Journal of Economic Structures, 7(18), 18. http://dx.doi.org/10.1186/s40008-018-0116-0

Mariolis, T., Rodousakis, N., and Katsinos, A., 2019. Wage Versus Currency Devaluation, Price PassThrough and Income Distribution: A Comparative Input-Output Analysis of the Greek and Italian Economies. Journal of Economic Structures, 8(9), 9. http://dx.doi.org/10.1186/s40008-019-01408

Mariolis, T., and Soklis, G., 2020. The Contribution of Primary Inputs to Price Formation: An InputOutput Analysis of the Greek Economy. Greek Economic Outlook, 41, 101-118.

Markaki, M. S., and Economakis, G., 2021. Measuring the International Structural Competitiveness and the Hierarchy of National Economies: The Case of the European Union. Research Square. http://dx.doi.org/10.21203/rs.3.rs-60232/v1

Mastronardi, J. L., Romero, A. C., and Chisari, O. O., 2012. Building an Input-Output Model for Buenos Aires City. REPEC, 40028. http://mpra.ub.uni-muenchen.de/40028.

Meng, B., Okamoto, N., Tsukamoto, Y., and Qu, C., 2009. Input-Output Based Economic Impact Evaluation System for Small City Development: A Case Study on Saemangeum's Flux City Design. Institute of Developing Economies (IDE), JETRO, Discussion Paper, 184.

Meng, B., Sato, H., and Nakamura, J., 2006. Interindustrial Structure in the Asia-Pacific Region: Growth and Integration, by Using 2000 AIO Table. Institute of Developing Economies (IDE), JETRO, Discussion Paper, 50.

Miller, E. R., 1989. Stability of Supply Coefficients and Consistency of Supply-Driven and DemandDriven Input-Output Models: A Comment. Environment and Planning A. Economy and Space, 21(8), 1113-1120. http://dx.doi.org/10.1068/a211113

Miller, E. R., and Blair, D. P., 2009. Input-Output Analysis: Foundations and Extensions: Cambridge University Press. http://dx.doi.org/10.1017/CBO9780511626982

Miyazawa, K., 1976. Input-Output Analysis and the Structure of Income Distribution (Vol. 116). Berlin: Springer Verlag. http://dx.doi.org/10.1007/978-3-642-48146-8

Muchdie, M., Imansyah, H. M., Kusmavan, M., and Al-Jufri, H., 2018. Import Components and Import Multipliers in Indonesian Economy: World Input-Output Analysis. Jurnal Economi dan Studi Pembangunan, 10(1), 88-102. http://dx.doi.org/10.17977/um002v10i12018p088

Nhung, H. N., Phong, V. N., Thai, Q. N., and Trinh, B., 2019a. Analyzing the Northern Key Economic Region of Vietnam Based on Interregional Input-Output Model. International Journal of 
Economics, Business and Management Studies, 6(1), 235-246. http://dx.doi.org/10.20448/802.61.235.246

Nhung, H. N., Thai, Q. N., Trinh, B., and Phong, V. N., 2019b. Rural and Urban in Vietnam Economic Structure. International Business Research, 12(3), 31-39. http://dx.doi.org/10.5539/ibr.v12n3p31

Okamoto, N., 2014. Does Regional Size Matter in Regionalization of Input-Output Table by the FLQ Formula? A Case Study of China. Discussion Papers of Institute of Economic Research, 222.

Oosterhaven, J., 1988. On the Plausibility of the Supply-Driven Input-Output Model. Journal of Regional Science, 28(2), 203-217. http://dx.doi.org/10.1111/j.1467-9787.1988.tb01208.x

Oosterhaven, J., 1989. The Supply-Driven Input-Output Model: A New Interpretation but Still Implausible. Journal of Regional Science, 29(3), 459-465. http://dx.doi.org/10.1111/j.14679787.1989.tb01391.x

Oosterhaven, J., 1996. Leontief's Versus Ghosian Price and Quantity Models. Southern Economic Journal, 62(3), 750-759. http://dx.doi.org/10.2307/1060892

Oosterhaven, J., 2017. Key Sector Analysis: A Note on the Other Side of the Coin. SOM Research Report, 17015.

Oosterhaven, J., 2019. Re-Thinking Input-Output Analysis. A Spatial Perspective: Springer International Publishing.

Oosterhaven, J., Eding, J. G., and Stelder, D., 2001. Clusters, Linkages and International Spillovers: Methodology and Policy Implications for the Two Dutch Mainports and the Rural North. Regional Studies, 35(9), 809-822. http://dx.doi.org/10.1080/00343400120090239

Oosterhaven, J., and Stelder, D., 2002. Net Multipliers Avoid Exaggerating Impacts: With a Bi-regional Illustration for the Dutch Transportation Sector. Journal of Regional Science, 42(3), 533-543. http://dx.doi.org/10.1111/1467-9787.00270

Oosterhaven, J., and Stelder, D., 2008. Syllabus Regional and Interregional I-O Analysis: University of Groningen, Faculty of Economics and Business.

Pham, Q. N., Trinh, B., and Nguyen, D. T., 2007. Economic Performance of Vietnam, 1976-2000: New Evidence from Input-Output Model. Working Papers of Development and Policies Research Center (DEPOCEN), 13.

Plane, D. A., and Rogerson, P. A., 1986. Dynamic flow modeling with interregional dependency effects: An application to structural change in the U.S. migration system. Demography, 23(1), 91-104. http://dx.doi.org/10.2307/2061411

Pnevmatikos, T., Niavis, S., and Polyzos, S., 2013. Evaluating Greek Economic Sectors' Regional Dynamics During the Pre and In-Crisis Period. MIBES Transactions International Journal, 7(1), 79-91. http://mtol.teithessaly.gr/vol7_2013.html.

Polenske, R. K., 2004. Leontief's "Magnificent Machine" and Other Contributions to Applied Economics. In E. Dietzenbacher and M. L. Lahr (Eds.), Wassily Leontief and Input-Output Economics (pp. 9-29): Cambridge University Press.

Ramos, C., and Moreno, B., 2013. Characterization of Spanish Economic Sectors from an Economic and Environmental Perspective: Evolution and Forecast of Greenhouse Gas Emissions. Regional and Sectoral Economic Studies, 13(2), 117-136.

Rickman, S. D., 2002. A Bayasian Forecasting Approach to Constructing Regional Input-Output Based Employment Multipliers. Papers in Regional Science, 81(4), 483-498. http://dx.doi.org/10.1111/j.1435-5597.2002.tb01245.x

Rogerson, A. P., and Plane, A. D., 1984. Modeling Temporal Change in Flow Matrices. Papers in Regional Science, 54(1), 147-164. http://dx.doi.org/10.1111/j.1435-5597.1984.tb00821.x

Romero, A. C., Mastronardi, J. L., Tarelli, P. J., and Haslop, F., 2019. The Regional Impact of Tourism When Data is Scarce. An Application to the Province of Salta. Tourism Planning \& Development, 17(4), 441-457. http://dx.doi.org/10.1080/21568316.2019.1673808

Sancho, F., 2012. Straightening Out the Concept of Direct and Indirect Input Requirements. Economic Bulletin, 32(1), 502-509. 
Sancho, F., 2013. Some Conceptual Difficulties Regarding "Net" Multipliers. The Annals of Regional Science, 51(2), 537-552. http://dx.doi.org/10.1007/s00168-012-0542-0

Soklis, G., 2014. Commodities' Commodity Content and Prices: Empirical Evidence from the InputOutput Tables of the French Economy. Investigacion Economica, 73(288), 35-57.

Sonis, M., Guilhoto, M. J. J., Hewings, D. J. G., and Martins, B. E., 1995. Linkages, Key Sectors and Structural Change: Some New Perspectives. The Developing Economies, 33(3), 233-270. http://dx.doi.org/10.1111/j.1746-1049.1995.tb00716.x

Sonis, M., and Hewings, D. J. G., 1998. Temporal Leontief Inverse. Macroeconomic Dynamics, 2(1), 89-114. http://dx.doi.org/10.1017/S1365100598006051

Sonis, M., Hewings, D. J. G., Okuyama, Y., and Guo, J., 1996. Japanese Regional Economic Structure Interpreted Through the Multiplier Product Matrix. Studies in Regional Science, 26(2), 1-20. http://dx.doi.org/10.2457/srs.26.2_1

Tadayuki, H., 2008. Quantitative Tourism Industry Analysis: Introduction to Input-Output, Social Accounting Matrix Modeling and Tourism Satellite Accounts. Canada: Charon Tec Ltd., A Macmillan Company, Elsevier Inc.

Temurshoev, U., and Oosterhaven, J., 2014. Analytical and Empirical Comparison of Policy-Relevant Key Sector Measures. Spatial Economic Analysis, 9(3), 284-308. http://dx.doi.org/10.1080/17421772.2014.930168

Teves, G. T. E. J. M., 2019. Measuring Inclusivity and Marginality: Determining the Accuracy of Various Location Quotient Approaches in Estimating the Philippine Regional Input-Output (IO) Coefficients. Paper presented at the First International Development Forum in Thailand: "Well Being, Social Inclusion and Sustainable Development", Faculty of Political Science, Chulalongkorn University.

Thai, Q. N., and Trinh, B., 2019. Analyze Industry and Construction Group Structure in Vietnam Economy for Sustainable Development. International Journal of Management Sciences and Business Research, 8(11), 108-121.

Thai, Q. N., Trinh, B., Duong, A. T., and Phong, V. N., 2019. Total Factor Productivity Through the Ghosh Model: The Paradox of Developing Countries? Sumerianz Journal of Economics and Finance, 2(12), 144-146.

Thai, Q. N., Trinh, B., Duong, A. T., and Phong, V. N., 2020. Research on Total Factor Productivity Through the Ghosh Model: The Paradox of Developing Countries. In L. A. F. Kwong (Ed.), Current Strategies in Economics and Management (Vol. 2, pp. 33-39): Book Publisher International. http://dx.doi.org/10.9734/bpi/csem/v2

Trinh, B., 2017. Interregional Structure Analysis Based on Three Regions of Vietnam. Advances in Social Sciences Research Journal, 4(7), 38-44. http://dx.doi.org/10.14738/assrj.47.2963

Trinh, B., 2020. Supply Size in Exports: Expansion Input-Output Analysis Approach. International Journal of Economics and Financial Research, 6(8), 201-206. http://dx.doi.org/10.32861/ijefr.68.201.206

Trinh, B., Kobayashi, K., Hoa, L. P., and Phong, V. N., 2012. An Economic Structural Change Comparison of Interactions Analysis Between Manufacturing and REST of Economic Activity: Application to Vietnam Economy Based on Input-Output Tables. Journal of Contemporary Management, 1(1), 1-13.

Trinh, B., and Phong, V. N., 2014. Economic Structure's Change Based on the Relationship Between Domestic Final Demand and Production, Value Added and Import. British Journal of Economics. British Journal of Economics. Management \& Trade, 4(10), 1512-1524. http://dx.doi.org/10.9734/BJEMT/2014/10160

Trinh, B., and Thai, N. Q., 2021. An Approach to Economics-Environmental Relations from Expanding the Input-Output System. Theoretical Economics Letters, 11(1), 56-62. http://dx.doi.org/10.4236/tel.2021.111004 
West, R. G., 1995. Comparison of Input-Output, Input-Output + Econometrics and Computable General Equilibrium Models at the Regional Level. Economic Systems Research, 7(2), 209-227. http://dx.doi.org/10.1080/09535319500000021

Yamada, I., 1961. Theory and Applications of Interindustry Analysis: Kinokuniya Bookstore Company.

Yasmin, T., and Bekhet, A. H., 2017. Sectoral Capabilities and Productive Structure: An Input-Output Analysis of the Key-Sectors of the Malaysian Economy. international Business Management, 2(2), 1-21.

Yotopoulos, A. P., and Nugent, B. J., 1973. A Balanced - Growth Version of the Linkage Hypothesis: A Test. The Quarterly Journal of Economics, 87(2), 157-171. http://dx.doi.org/10.2307/1882181

Zhang, S. Z., 2001. Iterative Method for Finding the Balanced Growth Solution of the Non-Linear Dynamic Input-Output Model and the Dynamic CGE Model. Economic Modelling, 18(1), 117132. http://dx.doi.org/10.1016/S0264-9993(00)00031-6

Zhong, Y. Y., and Tadayuki, H., 2013. Quantifying the Impacts of the Recent Economic Crisis on Regional Tourism Industry and Economy. Hospitality Review, 31(1), 1.

\section{Copyright}

This article is an open access article distributed under the terms and conditions of the Creative Commons Attribution-NonCommercial-NoDerivatives 4.0 International License. 